\title{
Comparative physiology of Synechococcus and Prochlorococcus: influence of light and temperature on growth, pigments, fluorescence and absorptive properties
}

\author{
Lisa R. Moore ${ }^{1}$, Ralf Goericke ${ }^{2}$, Sallie W. Chisholm ${ }^{1}$ \\ ${ }^{1}$ Ralf M. Parsons Laboratory 48-425, Department of Civil and Environmental Engineering, Massachusetts Institute of \\ Technology, Cambridge, Massachusetts 02139, USA \\ ${ }^{2}$ Marine Life Research Group, Scripps Institution of Oceanography, La Jolla, California 92093-0218, USA
}

\begin{abstract}
Prochlorococcus marinus is abundant and widespread throughout the world's oceans and always co-occurs geographically with the marine cyanobacterium Synechococcus. In the Atlantic Ocean, these 2 picoplankters exhibit different spatial and seasonal distributions. In order to better understand the ecology of these species, we measured growth and photoacclimation responses including fluorescence excitation $\left[F^{*}{ }_{\mathrm{ph}}(\lambda)\right]$ and in vivo absorption $\left[a^{*}{ }_{\mathrm{ph}}(\lambda)\right]$ spectra over a range of growth irradiances for P. marinus (clone SS120) and Synechococcus WH8103, both isolated from the Sargasso Sea. To explore the physiological diversity of $P$. marinus, we measured the physiological responses of another P. marinus clone, MED4, isolated from the Mediterranean Sea. Growth rate as a function of temperature was also examined for all 3 clones. P. marinus SS120 and Synechococcus WH8103 have different temperature optima for growth, but these do not explain the different latitudinal distributions in the North Atlantic. P. marinus SS120 is adapted for growth at low light intensities relative to Synechococcus WH8103, which is consistent with the relative depth distribution of $P$. marinus and Synechococcus in the field. The light-dependent growth response of $P$. marinus MED4 is more similar to Synechococcus WH8103 than to $P$. marinus SS120. The unique pigment content of $P$. marinus (which contain divinyl chlorophylls $a$ and $b$ ) results in maximal absorbance in the blue wavelengths. The high total chl $b / c h l$ a ratio of $P$. marinus SS120 enables it to absorb more light, grow faster than Synechococcus WH8103 (and P. marinus MED4) at low light intensities, and presumably to outcompete Synechococcus in the deep euphotic zone. At high growth irradiances, $P$. marinus SS120 contains measureable amounts of normal (monovinyl) $\mathrm{chl} b$, whereas this pigment was not found in $P$. marinus MED4 at any growth irradiance. Photoacclimative changes in pigment ratios, and not package effect, account for most of the changes in $a^{*}{ }_{\mathrm{ph}}(\lambda)$ and $F^{*}{ }_{\mathrm{ph}}(\lambda)$ with light intensity for all 3 picoplankters. At high light intensities, zeaxanthin contributes substantially to $a^{*}{ }_{p h}(\lambda)$ in the blue, but appears to transfer little or no excitation energy to the reaction centers, based on $F{ }_{\mathrm{ph}}(\lambda)$ measurements. For P. marinus, high absorption in the blue due to divinyl chl $a$ and $b$ relative to normal chl $a$ and $b$, absorption due to zeaxanthin, and small cell size result in unusually high $a^{*}{ }_{\mathrm{ph}}$ (blue) relative to $a_{\mathrm{ph}}^{*}(\mathrm{red})$.
\end{abstract}

KEY WORDS: Prochlorococcus marinus · Synechococcus · Light - Absorption - Pigments · Divinyl chlorophyll $a$

\section{INTRODUCTION}

Prochlorococcus marinus (Chisholm et al. 1992) is ubiquitous throughout the euphotic zone in tropical and subtropical oceans and contributes substantially to photosynthetic biomass and primary production (Chis- holm et al. 1988, Campbell \& Vaulot 1993, Goericke \& Welschmeyer 1993). It has a unique suite of pigments, which includes divinyl chlorophyll $a\left(\mathrm{chl} a_{2}\right.$ ) as the principal light-harvesting pigment, and divinyl chl $b$ $\left(\operatorname{chl} b_{2}\right)$, zeaxanthin, $\alpha$-carotene and a chl $c$-like pigment as the main accessory pigments (Goericke \& 
Repeta 1992). Based on flow cytometric signatures and/or the presence of chl $a_{2}, P$. marinus has been found in the Atlantic Ocean (Neveux et al. 1989, Olson et al. 1990, Veldhuis \& Kraay 1990), the tropical and subtropical Pacific (Chavez et al. 1991, DiTullio et al. 1992, Campbell \& Vaulot 1993), the Mediterranean Sea (Vaulot et al. 1990, Vaulot \& Partensky 1992), and the Red Sea (Veldhuis \& Kraay 1993). Synechococcus has always been found in regions where $P$. marinus is present, although $P$. marinus often extends to lower depths (Olson et al. 1990, Campbell \& Vaulot 1993, Veldhuis \& Kraay 1993). P. marinus is usually found in abundances reaching $10^{4}$ to $10^{5} \mathrm{cells} \mathrm{ml}^{-1}$ (Olson et al. 1990, Vaulot et al. 1990, Chavez et al. 1991, Campbell \& Vaulot 1993, Veldhuis \& Kraay 1993) and can contribute up to $65 \%$ of total $\mathrm{chl}$ a, i.e. the sum of $\mathrm{chl} a_{1}$ and chl $a_{2}$ (Veldhuis \& Kraay 1990, Goericke \& Welschmeyer 1993). Goericke \& Welschmeyer (1993) measured the growth rate of $P$. marinus by measuring the incorporation of ${ }^{14} \mathrm{C}$ into $\mathrm{chl} \mathrm{a}_{2}$. Surface layer growth rates of $P$. marinus ranged from 0.1 to $0.5 \mathrm{~d}^{-1}$ and did not vary systematically over the seasons; growth rates at the subsurface chlorophyll maximum (SCM) ranged from 0.04 to $0.16 \mathrm{~d}^{-1}$. These authors also calculated that the seasonally averaged contribution of $P$. marinus to the total primary productivity in the Sargasso Sea was $25 \%$.

Prochlorococcus marinus has been observed in the North Atlantic only when surface water temperatures were above $15^{\circ} \mathrm{C}$, suggesting that low temperature can influence the $P$. marinus distribution (Olson et al. 1990, Veldhuis et al. 1993). In the North Atlantic, P. marinus blooms after Synechococcus does (after the onset of spring stratification) and establishes a subsurface abundance maximum usually associated with the deep chlorophyll maximum (Olson et al. 1990). P. marinus is generally present throughout the euphotic zone during the winter, fall and spring, but during the early summer the majority of cells are largely restricted to the SCM (Olson et al. 1990). In the North Pacific (station ALOHA), P. marinus is uniformly abundant in the surface of the euphotic zone and declines in numbers with depth during all seasons (Campbell \& Vaulot 1993). Synechococcus populations in both the North Atlantic and North Pacific are uniformly abundant in the surface and have no subsurface maximum yearround (Olson et al, 1990, Campbell \& Vaulot 1993). P. marinus populations are more abundant and extend deeper in the water column than Synechococcus populations throughout most of the year in the oligotrophic North Atlantic (Olson et al. 1990, Veldhuis \& Kraay 1993) and Pacific (Campbell \& Vaulot 1993).

Prochlorococcus marinus seems to be particularly well adapted to growth in low light, as determined by laboratory studies (Partensky et al. 1993) and distribu- tions observed in the field. At the $1.6 \%$ light level in the Sargasso Sea, $P$. marinus was found to grow twice as fast as other phytoplankton, based on ${ }^{14} \mathrm{C}$ incorporation into chl $a_{2}$ and chl $a_{1}$ (Goericke \& Welschmeyer 1993). Morel et al. (1993) suggested that the ability of $P$. marinus to dominate the algal population in the deeper euphotic zone may be due, in part, to the optical properties of $P$. marinus. Because of its small size, it has a higher absorption efficiency than Synechococcus, even though both are well suited for absorbing the blue light available in oligotrophic waters (Morel et al. 1993).

In stratified waters, photoacclimation (used here to describe reversible light-induced alterations in the physiological or morphological characteristics of a population) of Prochlorococcus marinus populations is reflected by a change in cellular concentrations of chl $a_{2}$ and in mean cellular fluorescence (Olson et al. 1990, Veldhuis \& Kraay 1990, 1993, Campbell \& Vaulot 1993). Goericke \& Repeta (1993) reported dramatic changes of the ratio of chl $b_{2} / \mathrm{chl} a_{2}$ with depth at a station in the southern Sargasso Sea, ranging from 0.1 in the surface layer to 3.0 below the SCM.

These field observations led us to examine how light and temperature affect the growth rates of Prochlorococcus marinus and Synechococcus and to analyze the effects of light on the pigment composition of the cells. While differences in nutrient utilization are undoubtedly a critical environmental determinant, this factor could not be studied as axenic cultures have not yet been established for these species. In addition, we examined the extent of physiological differences between $2 P$. marinus clones isolated from different parts of the world: the Sargasso Sea and the Mediterranean Sea.

\section{METHODS}

Culture conditions and growth measurements. Clonal cultures of WH8103, a high phycourobilin (PUB) Synechococcus strain isolated from the Sargasso Sea (obtained from John Waterbury, Woods Hole Oceanographic Institution, MA, USA), and Prochlorococcus marinus isolated at $120 \mathrm{~m}$ from the Sargasso Sea ( $P$. marinus SS120; designated CCMP-1375 at the Center for the Culture of Marine Phytoplankton, Bigelow Laboratory for Ocean Sciences, West Boothbay Harbor, ME, USA) and from the surface of the Mediterranean Sea (P. marinus MED4; CCMP-1378) were maintained in a modified $\mathrm{K} / 10$ medium (Chisholm et al. 1992) supplemented with $50 \mu \mathrm{M}$ urea and $10 \mathrm{nM} \mathrm{NiCl}_{2}$. For measuring growth rate as a function of temperature, cultures were grown in glass test tubes in an aluminum temperature-gradient bar on a $14 \mathrm{~h}$ 
light: $10 \mathrm{~h}$ dark cycle at $90 \mu \mathrm{E} \mathrm{m} \mathrm{m}^{-2} \mathrm{~s}^{-1}$, incident from below. For light experiments, cultures were grown in $250 \mathrm{ml}$ polycarbonate bottles on a $14 \mathrm{~h}$ light: $10 \mathrm{~h}$ dark cycle at $24 \pm 1{ }^{\circ} \mathrm{C}$. Different light levels and quality were generated using cool white fluorescent lamps in combination with neutral density (Rosco \#3402, 3403, 3404 ) and blue (Rosco \#69) filters. The blue filter, which transmits maximally at $440 \mathrm{~nm}$ with half-maximum transmission width of $130 \mathrm{~nm}$, provides a light environment similar to that found in the deep euphotic zone of the Sargasso Sea (Jerlov 1976). The growth irradiance $\left(\mu \mathrm{E} \mathrm{m}^{-2} \mathrm{~s}^{-1}\right)$ for the white and blue light regimes was matched using a recently calibrated quantum scalar irradiance meter (Biospherical QSL100, San Diego, CA, USA). Of the white light irradiance, $47 \%$ is comprised of wavelengths between 380 and $540 \mathrm{~nm}$, corresponding approximately to the wavelengths of light provided by the blue filters. Thus, the cells grown in white light had approximately half the energy in the blue wavelengths as the cells grown only in blue light of comparable total irradiance.

Cultures were acclimated to each irradiance level for several generations (until the mean fluorescence per cell was constant) before data was collected. Replicates for all growth experiments represent serial transfers from the same 'parent' culture. Cells were harvested in exponential growth phase for the pigment analyses, in vivo absorption spectra, and fluorescence excitation and emission spectra.

Growth rate was determined by sampling each culture at the same time of day over several generations using a Becton-Dickinson FACScan (San Jose, CA) flow cytometer to enumerate the cells. This instrument employs an argon-ion laser with $488 \mathrm{~nm}$ line as the excitation source. Fluorescence emission was obtained using a long-pass filter (>650 nm) for chlorophyll (red fluorescence) and a narrow band-pass filter ( $585 \mathrm{~nm}$, half-maximum transmission width $=42 \mathrm{~nm}$ ) for phycoerythrin (orange fluorescence). Mean chlorophyll fluorescence per cell is presented relative to standard fluorescent beads $(0.57 \mu \mathrm{m}$ diameter; Polysciences, Inc., Warrington, PA, USA). Data were analyzed using CYTOPC software (Vaulot 1989).

Pigment measurements. Prochlorococcus marinus and Synechococcus WH8103 cultures (25 to $75 \mathrm{ml}$ ) were collected on $25 \mathrm{~mm}$ Whatman GF/F filters using vacuum pressure of $<75 \mathrm{~mm} \mathrm{Hg}$. Filters were stored in liquid nitrogen for 1 to 6 mo. For pigment analysis by reverse-phase high-pressure liquid chromotography (RP-HPLC), filters were extracted as described in Goericke \& Welschmeyer (1993). All samples were analyzed on a C-18 column-based RP-HPLC system using a Rainin Dynamax $10 \mathrm{~cm} 3 \mu \mathrm{m} \mathrm{C}-18$ column; the following solvents: A (MeOH:aqueous ammonium acetate, 85:15), B (MeOH), and $\mathrm{C}$ (acetone); and a linear ternary gradient (time; \% solvent A, \% solvent B, $\%$ solvent $\mathrm{C})$ : $(0 \mathrm{~min} ; 100,0,0),(5 \mathrm{~min} ; 6,92,2)$, $(12 \mathrm{~min} ; 0,100,0),(15 \mathrm{~min} ; 0,90,10),(18 \mathrm{~min} ; 0,40,60)$, (20 min; $0,20,80),(24 \mathrm{~min} ; 0,20,80)$, with a flow rate of $1.5 \mathrm{ml} \mathrm{min}{ }^{-1}$. The coefficient of variation for replicate analyses on this system was concentration dependent; for the major pigments discussed here it was in the range 1 to $5 \%$.

Selected samples were also analyzed on a C-8 column-based RP-HPLC system (Goericke \& Repeta 1993). On this system, chl $a_{1}$ is well separated from $\operatorname{chl} a_{2}$ and its stereoisomer chl $a_{2}{ }^{\prime}$. Chl $b_{1}$ and chl $b_{2}$ are partially separated. The chromatographic systems were calibrated with zeaxanthin, $\alpha$-carotene, chl $b_{2}$, and chl $a_{2}$ isolated from low-light cultures of Prochlorococcus marinus (clone MED4), and with chl $a_{1}$ and $\mathrm{chl} b_{1}$ isolated from spinach. Pigments were quantified (Waters 990 photodiode array detector) using integrated absorbance at $440 \mathrm{~nm}$ and the extinction coefficients given by Goericke \& Repeta (1993). The chl $b_{1}$ / chl $b_{2}$ concentration ratio was determined for all samples from the ratio of the integrated absorbances at 468 and $478 \mathrm{~nm}$ (Goericke \& Repeta 1993).

All pigments were identified based on retention time and on-line Vis-spectra. Mass spectra of chl $a_{2}, \mathrm{chl} b_{1}$, and total chl $b$, i.e. the sum of chl $b_{1}$ and chl $b_{2}$, were recorded using liquid secondary ion mass spectrometry (LSIMS) with a VG dynamic LSIMS probe, acetone as a solvent and nitrobenzylalcohol as a matrix with polyethyleneglycol 600 and 1000 as an internal standard. Samples were ionized with a cesium ion gun operated at $35 \mathrm{kV}$. Pigments for this analysis were isolated from a higher plant and from pooled extracts of high-light cultures of Prochlorococcus marinus SS120.

Absorption spectra. An in vivo absorption spectrum for cells concentrated on a filter was run for each sample using a Beckman DU-7 (Irvine, CA) singlebeam spectrophotometer following methods outlined by Mitchell \& Kiefer (1988). Absorption spectra of cells collected on filters, rather than spectra of whole cell suspensions, were used in order to compare lab results to field results. Scans were run with a $2 \mathrm{~nm}$ bandpass at $600 \mathrm{~nm} \mathrm{~min}{ }^{-1}$. All samples were filtered using Whatman $\mathrm{GF} / \mathrm{F}$ filters at low vacuum pressure $(<75 \mathrm{~mm} \mathrm{Hg})$, placed on a glass slide, and run within 2 to $3 \mathrm{~min}$ of filtration to avoid potential artifacts (Stramski 1990). A GF/F filter saturated with culture medium was used as the blank, and the optical density of the filter sample $\left(O D_{\mathrm{f}}\right)$ at $750 \mathrm{~nm}$ was subtracted from all spectra to obtain $O D_{\mathrm{f}}(\lambda)$.

In order to correct the absorption spectra of filter samples for the effects of pathlength amplification, a $\beta$-correction algorithm was empirically derived for our spectrophotometer using Synechococcus WH8103 and 
Prochlorococcus marinus, following published methods (Mitchell \& Kiefer 1988, Mitchell 1990). Each species was concentrated by centrifugation $(11000 \mathrm{rpm}$, $19000 \times \mathrm{g}, 30 \mathrm{~min}, 10^{\circ} \mathrm{C}$ ), and serial dilutions were made to cover a range of optical densities. Absorption spectra for these cell suspensions were obtained with an opal diffuser (Shibata 1958). For the same culture, there were no differences in shape between the absorption spectrum obtained using an opal diffuser and that obtained using an integrating sphere $(\mathrm{H}$. Sosik \& L. R. Moore unpubl. data). For each absorption spectrum of a cell suspension, a corresponding spectrum was determined using an equivalent pathlength (clearance area of filter multiplied by the length of the spectrophotometer cuvette) of cells collected on a filter.

The relationship between the $O D_{f}(\lambda)$ and the optical density of cells in suspension, $O D_{s}(\lambda)$, fits a secondorder polynomial:

$$
O D_{\mathrm{s}}(\lambda)=a O D_{\mathrm{f}}(\lambda)+b\left[O D_{\mathrm{f}}(\lambda)\right]^{2}
$$

where $a$ and $b$ are the coefficients (inset, Fig. 1). The in vivo absorption spectrum for each phytoplankton culture was calculated as follows:

$$
a^{*}{ }_{\text {ph }}(\lambda)=2.3 A_{\mathrm{f}}\left[O D_{\mathrm{s}}(\lambda)\right] / V_{\mathrm{f}} C_{\mathrm{i}}
$$

where $A_{\mathrm{f}}$ is the area of the cells on the filter $\left(\mathrm{m}^{2}\right), V_{\mathrm{f}}$ is the volume of cells filtered $(\mathrm{ml}), O D_{\mathrm{s}}(\lambda)$ is the optical density of the suspension obtained by applying the correction algorithm (Eq. 1) to the measured values of $O D_{\mathrm{f}}(\lambda), C_{\mathrm{i}}$ is the amount of chl $a_{1}$ or chl $a_{2}$ in the sample ( $\mathrm{mg} \mathrm{ml}^{-1}$ ), and the constant 2.3 converts units from log of base 10 to natural $\log$ (Mitchell \& Kiefer 1988).
The relationship between $O D_{\mathrm{f}}$ and $O D_{\mathrm{s}}$ obtained for Synechococcus WH8103 differed (up to $30 \%$ at $O D_{\mathrm{f}}=0.4$ ) from that found previously for other phytoplankton species, including an unidentified strain of Synechococcus (Mitchell 1990) and Synechococcus WH7803 (Cleveland \& Weidemann 1993). The relationship found for Prochlorococcus marinus differed even more, up to $50 \%$ lower $O D_{\mathrm{s}}$ is obtained when the optical density of cells filtered onto a GF/F filter reaches 0.4 . To verify that the different $\beta$ correction found for Synechococcus WH8103 and P. marinus in this study was not due to any systematic or procedural error, absorption of Thalassiosira weissflogii cells was also measured on our system and found to be consistent with that found by other researchers for other phytoplankton (Fig. 1) (Mitchell 1990, Cleveland \& Weidemann 1993). A greater correction for Synechococcus WH8103 cells, and the even smaller P. marinus cells, may result from their small size. It is likely that the cells become embedded within the filter matrix rather than creating a layer on top of the filter, and the interaction of the filter scattering and the cell scattering (as small as it is; Morel et al. 1993) might increase the pathlength of amplification, similar to a thicker filter pad (cf. Mitchell 1990). Culture conditions such as nutrients and light which affect cell size might influence the extent of the $\beta$ correction; however, this effect deserves more study.

The unique $\beta$ correction of Prochlorococcus marinus and Synechococcus WH8103 becomes particularly important when estimating photosynthetic quantum yield. Depending on the optical density of the sample, if the $\beta$-correction algorithm for other phytoplankton is used

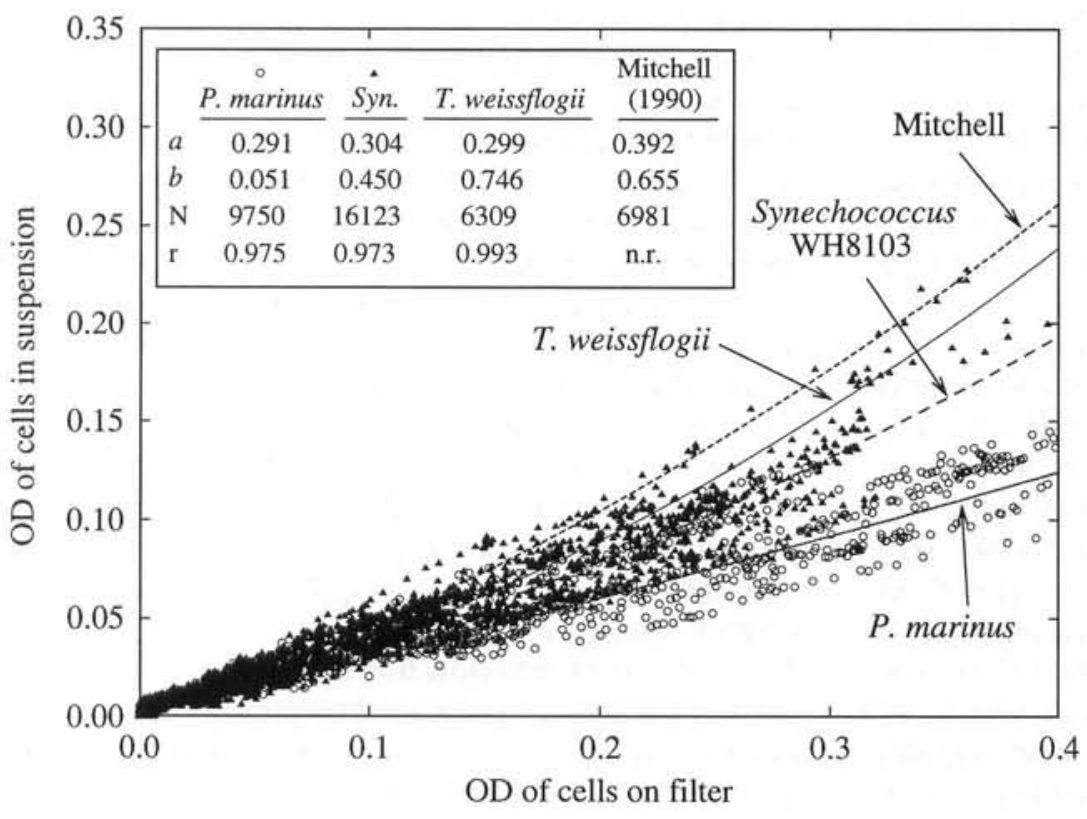

Fig. 1. Relationship between the optical density $(O D)$ of cells measured in suspension and on a filter for Synechococcus WH8103 (4) and Prochlorococcus marinus (o) from this study compared to the relationship obtained for Thalassiosira weissflogii in this study (individual data points not shown) and obtained by Mitchell (1990) for a collection of phytoplankton species, including Synechococcus. Inset: coefficients for Eq. (1) obtained by fitting $\mathrm{N}$ data points to a second-order polynomial. r: correlation coefficient; n.r.: not reported 
for P. marinus (e.g. Partensky et al. 1993), the absorption spectrum could be overestimated by as much as a factor of 2 in the blue, resulting in a higher spectrally weighted chl a-specific absorption and, consequently, a lower photosynthetic quantum yield. Thus, the relatively high maximum quantum yields calculated by Partensky et al. (1993) would actually be higher if samples with $O D_{\mathrm{f}}>0.1$ were used and our P. marinusspecific $\beta$ correction were used.

Spectral reconstruction. Whole-cell absorption spectra $\left[a_{\mathrm{ph}}(\lambda) ; \mathrm{m}^{-1}\right]$ were reconstructed and compared to in vivo absorption spectra as follows (Mann \& Myers 1968, Bidigare et al. 1987, 1989a, b):

$$
a_{\mathrm{ph}}(\lambda)=\Sigma\left[a_{i}(\lambda)\right] c_{i}
$$

where $a_{i}(\lambda)$ is the spectral specific absorption coefficient for each pigment, $i$, and $c_{i}$ is the volume-based concentration $\left(\mathrm{mg} \mathrm{m}^{-3}\right)$ of pigment $i$. The individual pigment-specific absorption coefficients $\left[a_{i}(\lambda)\right]$ (Fig. 2) were determined by normalizing the HPLC-generated absorption spectra to the weight-specific absorption coefficient (Goericke \& Repeta 1993), multiplying by 2.3 to convert from log of base 10 to natural log units, and shifting the wavelength of the pigment spectra as follows: (1) chl $a_{2} a_{i}(\lambda)$ was shifted to the red by $6 \mathrm{~nm}$ for wavelengths greater than $480 \mathrm{~nm}$; (2) zeaxanthin $a_{i}(\lambda)$ was shifted to the red by $10 \mathrm{~nm} ;(3)$ the $a_{i}(\lambda)$ for $\alpha$-carotene and the unknown carotenoid were shifted by $6 \mathrm{~nm}$ to the red; and (4) no shift was made for $\mathrm{chl} b_{2}$ and the chl $c$-like $a_{i}(\lambda)$. The wavelength shifts were the best matches for the in vivo absorption maxima (see Fig. 11).

Fluorescence spectra. Because a spectrofluorometer was not readily available, samples for fluorescence excitation and emission spectra were fixed with $0.125 \%$ glutaraldehyde (Tousimis, Rockville, MD, USA) and

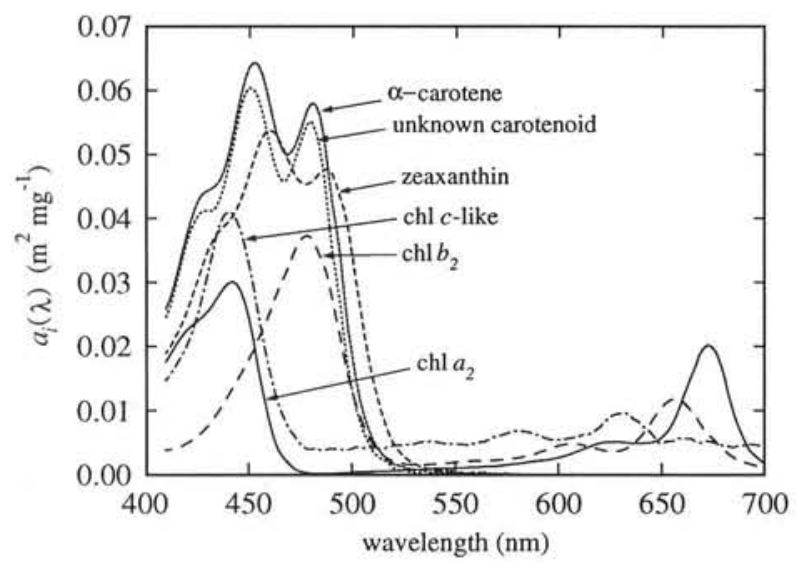

Fig. 2. Pigment-specific absorption coefficients $\left[a_{i}(\lambda)\right]$ for the different pigments in Prochlorococcus marinus, wavelength shifted to match the in vivo absorption peaks. Each pigment is designated by a different line type frozen in liquid nitrogen for later analysis (Vaulot et al. 1989). A SLM-Aminco (Champagne-Urbana, IL, USA) SPF-500 spectrofluorometer with a Xenon arc lamp as the excitation source was used for the fluorescence excitation and emission spectra. Excitation spectra were determined by measuring fluorescence emission at $680 \mathrm{~nm}$ (the wavelength of maximum emission for both Prochlorococcus marinus and Synechococcus WH8103) as a function of excitation wavelength. Measurements were obtained in $1 \mathrm{~nm}$ increments $(2 \mathrm{~nm}$ excitation band width) from 400 to $660 \mathrm{~nm}$ in 'ratio mode' which corrects for spectral variation due to the lamp. A media blank was subtracted from each spectrum. Quantum corrected excitation spectra were obtained by measuring the absorption and fluorescence excitation spectra of pure chl $a_{1}, \mathrm{chl} b_{1}$ and phycoerythrin (Sigma, St. Louis, MO, USA), calculating the ratio of fluorescence excitation to absorption as a function of wavelength for these standards, and correcting the spectrum of each sample by dividing by this ratio. The rhodamineB method of Melhuish (1962) was not appropriate for the spectrofluorometer used in this study.

To evaluate the influence of preservation on the analysis, spectra run on fresh aliquots and thawed aliquots which had been fixed and frozen were compared. For Prochlorococcus marinus SS120, the amplitude of the fluorescence excitation peak at $450 \mathrm{~nm}$ (due to $\mathrm{chl} \mathrm{a}_{2}$ ) did not change, whereas the peak at $480 \mathrm{~nm}$ (due predominantly to $\mathrm{chl} b_{2}$ ) was reduced by $18 \%$ in the fixed and frozen sample relative to the fresh sample. In P. marinus MED4, the chl $a_{2}$ and $c h l b_{2}$ fluorescence excitation peaks were reduced 22 and $12 \%$, respectively, by the preservation process. Although these differences were significant, they did not obscure the systematic intraspecies changes in fluorescence spectra which accompanied changes in light intensity. In contrast, the changes in fluorescence excitation due to preservation for Synechococcus WH8103 $40 \%$ decrease in both phycoerythrin peaks with a concomitant increase of $27 \%$ in the chl $a_{1}$ fluorescence excitation peak) were too large to allow meaningful interpretation of the trends.

\section{RESULTS AND DISCUSSION}

\section{Temperature optima}

The 2 Prochlorococcus marinus clones had the same optimal growth temperature of $24^{\circ} \mathrm{C}$, but neither would grow at $28^{\circ} \mathrm{C}$, the optimum for Synechococcus WH8103 (Fig. 3). Between 15 and $22^{\circ} \mathrm{C}$, however, the growth rates were quite similar for all 3 strains. Synechococcus WH8103 would not grow below $15^{\circ} \mathrm{C}$ under the conditions used in this study, differing from results previously 


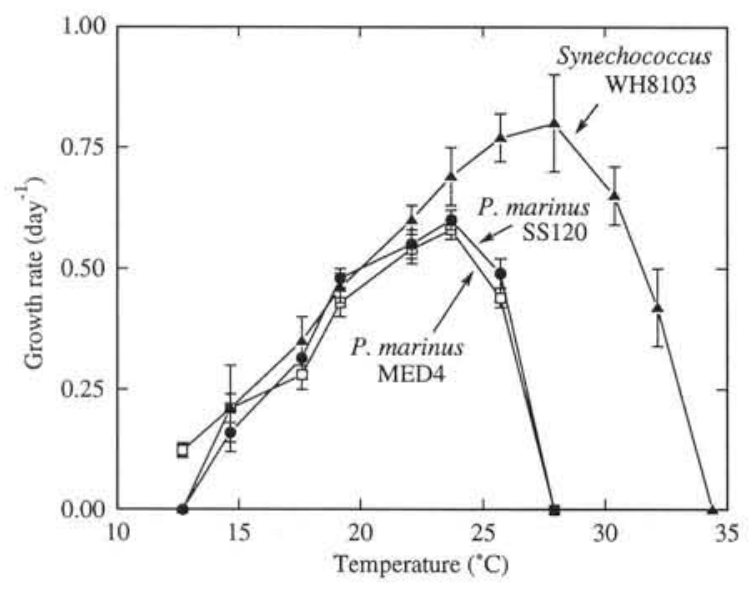

Fig. 3. Growth rate as a function of temperature for 3 oceanic picoplankters: Prochlorococcus marinus SS120 (•), P. marinus MED4 (ㅁ) and Synechococcus WH8103 (4). Cultures were maintained at $93 \mu \mathrm{E} \mathrm{m}^{-2} \mathrm{~s}^{-1}$ under a $14 \mathrm{~h}$ light: $10 \mathrm{~h}$ dark regime.

Error bars are $1 \mathrm{SD}$ from the mean based on 2 or 3 cultures

reported for several other marine Synechococcus clones (Waterbury et al. 1986, Castenholtz \& Waterbury 1989). The relatively low upper-limit growth temperature for the 2 P. marinus clones most likely is strain-specific, since $P$. marinus has been detected at water temperatures as high as $28^{\circ} \mathrm{C}$ in the equatorial and south Pacific (R. Olson, E. Zettler, J. Dusenberry \& B. Binder unpubl. data), the north Pacific (Campbell \& Vaulot 1993) and the Red Sea (Veldhuis \& Kraay 1993).

Of the 3 clones examined in this study, only Prochlorococcus marinus MED4 grew at a temperature of $12.5^{\circ} \mathrm{C}$, comparable to that of the Mediterranean Sea in wintertime (Vaulot et al. 1990). The lower temperature limit for growth of $P$. marinus SS120 is consistent with the observation that $P$. marinus has only been detected in the North Atlantic when surface temperatures are greater than $15^{\circ} \mathrm{C}$ (Olson et al. 1990, Veldhuis et al. 1993). However, the differences in optimal growth temperature cannot account for the difference in latitudinal and seasonal distributions of $P$. marinus and Synechococcus seen in the North Atlantic (Olson et al. 1990, Goericke \& Welschmeyer 1993, Veldhuis et al. 1993). The depth-integrated abundance of $P$. marinus is the same as that of Synechococcus during the winter in the North Atlantic but is greater than that of Synechococcus at other times of the year when the surface temperature ranges from 22 to $27^{\circ} \mathrm{C}$ (Olson et al. 1990).

\section{Light-dependent growth rates}

The light-saturated, maximum growth rates $\left(\mu_{\max }\right)$ for the 2 Prochlorococcus marinus clones were similar: $0.53 \pm 0.06 \mathrm{~d}^{-1}$ for P. marinus SS120 (Fig. 4A) and
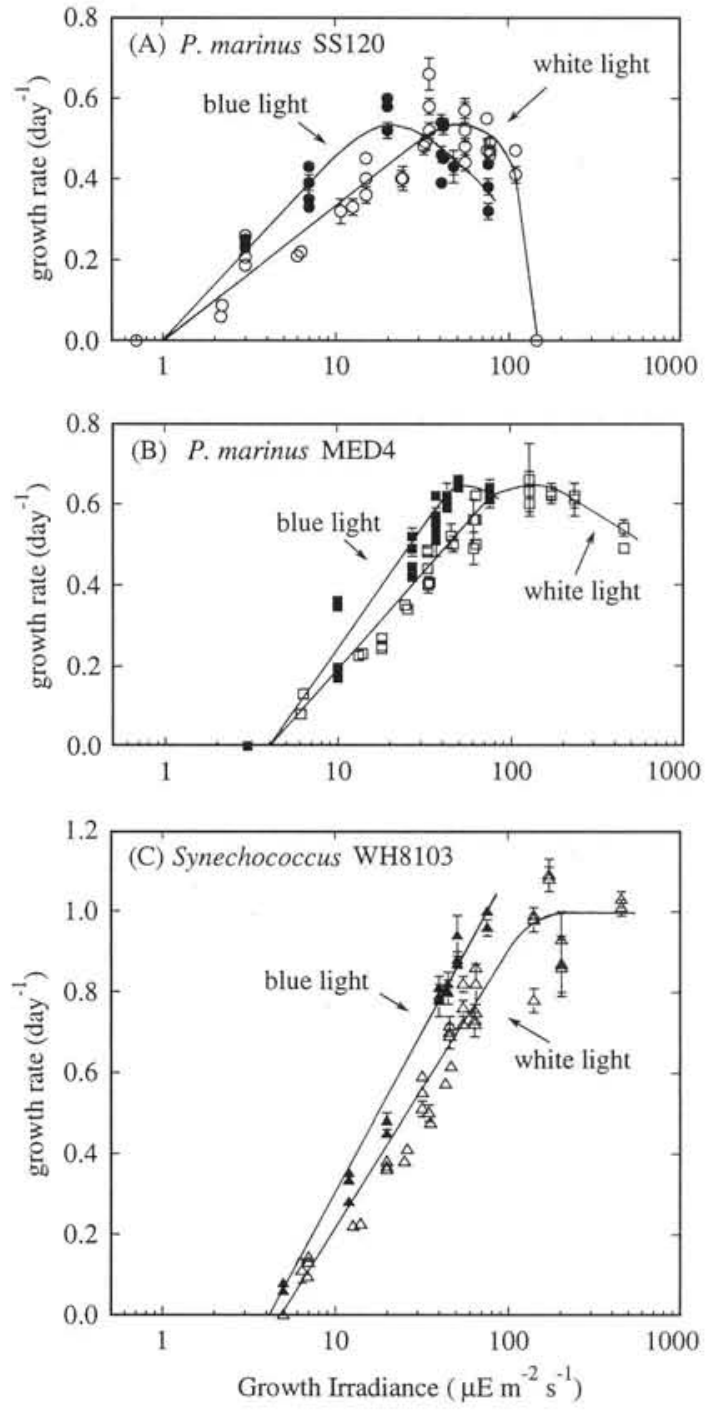

Fig. 4. Growth rate $( \pm \mathrm{SD})$ as a function of both white and blue light irradiance. Cultures were maintained at $24.5^{\circ} \mathrm{C}$ under a $14 \mathrm{~h}$ light: $10 \mathrm{~h}$ dark regime. Cultures were adapted to the growth irradiance for at least 10 generations. Open symbols: white-light-grown cells; closed symbols: blue-light-grown cells. (A) Prochlorococcus marinus SS120, (B) P. marinus MED4, (C) Synechococcus WH8103

$0.63 \pm 0.06 \mathrm{~d}^{-1}$ for $P$. marinus MED4 (Fig. 4B). The $\mu_{\max }$ for Synechococcus WH8103 was higher $\left(1.0 \pm 0.1 \mathrm{~d}^{-1}\right)$ (Fig. 4C). P. marinus SS120 (which was isolated from $120 \mathrm{~m}$ ) had a significantly lower compensation light intensity $\left(I_{\text {comp }}\right)$ for growth (the $95 \%$ confidence interval about $I_{\text {comp }}$ did not overlap with those of $P$. marinus MED4 and Synechococcus WH8103) and grew faster at lower light levels than both $P$. marinus MED4 (which was isolated from the surface; cf. Partensky et al. 1993) and Synechococcus WH8103 (Table 1). P. marinus SS120 had positive growth rates at light intensities about 5 times lower than Synechocccus 
Table 1. Light-dependent growth parameters $\left(\mu \mathrm{E} \mathrm{m} \mathrm{m}^{-2} \mathrm{~s}^{-1}\right)$ for Prochlorococcus marinus and Synechococcus cultures grown in white and blue light. $I_{\text {comp: }}$ compensation light level at which no growth occurs $(=x$-intercept for a linear fit to the light-limited region of the $\mu$ vs $\log (I)$ growth curve). Values in parentheses are the $95 \%$ confidence interval about $I_{\text {comp. }} I_{\max }$ : light level at which growth rate reaches a maximum; $I_{\text {inhib: }}$ irradiance at which growth rate is first inhibited due to excess light

\begin{tabular}{|lllcr|}
\hline & & $I_{\text {comp }}$ & $I_{\max }$ & $I_{\text {inhib }}$ \\
\hline P. marinus & White & $1(0.4-2.4)$ & $37 \pm 8$ & 110 \\
SS120 & Blue & $1(0.4-1.4)$ & $17 \pm 3$ & 50 \\
P. marinus & White & $4(2.6-6.7)$ & $90 \pm 13$ & 450 \\
MED4 & Blue & $4(2.0-5.9)$ & $49 \pm 8$ & 80 \\
Synechococcus & White & $5(3.5-8.4)$ & $142 \pm 21$ & $>450$ \\
WH8103 & Blue & $4(3.5-6.1)$ & $>80$ & $>80$ \\
& & & & \\
\hline
\end{tabular}

WH8103 (Fig. 4A, C). At the $I_{\text {comp }}$ for Synechococcus WH8103, for example, P. marinus SS120 grew at about $0.3 \mathrm{~d}^{-1}$. At $10 \mu \mathrm{E} \mathrm{m} \mathrm{m}^{-2} \mathrm{~s}^{-1}$ of blue light (typical of the wavelengths which penetrate deep in oligotrophic waters), the growth rate of $P$. marinus SS120 was about twice that of the other 2 picoplankters. These results are consistent with field observations which have shown that $P$. marinus extends deeper into the euphotic zone than Synechococcus (Chisholm et al. 1988, Olson et al. 1990, Campbell \& Vaulot 1993, Veldhuis et al. 1993) and that $P$. marinus grows faster than other phytoplankton by a factor of 2 at the $1.6 \%$ light level in the Sargasso Sea (Goericke \& Welschmeyer 1993).

Growth of Prochlorococcus marinus SS120 was inhibited at light intensities greater than $37 \mu \mathrm{E} \mathrm{m}^{-2} \mathrm{~s}^{-1}$, and it did not grow at $140 \mu \mathrm{E} \mathrm{m}^{-2} \mathrm{~s}^{-1}$, even after a several day adjustment period employing small incremental increases in irradiance (as suggested by Kana \& Glibert 1987). Photoinhibition of this strain at relatively low growth irradiances is not consistent with the distribution of $P$. marinus in the Sargasso Sea, where they are present (Olson et al. 1990) and growing (Goericke \& Welschmeyer 1993) in the surface waters when light intensities are in excess of $200 \mu \mathrm{E} \mathrm{m} \mathrm{m}^{-2} \mathrm{~s}^{-1}$. In the surface layer during the winter, growth of $P$. marinus is comparable to the growth rates of the other phytoplankton, and during the summer, $P$. marinus grow at a rate corresponding to $60 \%$ of the growth rate of the other phytoplankton (Goericke \& Welschmeyer 1993). The difference between our laboratory data and the field data could be explained by physical mixing (which could modulate the light regime experienced by these cells in the field), or by the existence of 2 (or more) different strains of $P$. marinus in the Sargasso Sea - one adapted for growth at high light, and one (e.g. P. marinus SS120) adapted for growth deep in the euphotic zone.
The light-dependent growth response of Prochlorococcus marinus MED4 has characteristics distinct from $P$. marinus SS120 and is consistent with characteristics expected for a high-light-adapted strain. The $I_{\max }$ for $P$. marinus MED4, for example, was more than twice that for $P$. marinus SS120 and more similar to the $I_{\max }$ for Synechococcus WH8103 (Table 1). P. marinus MED4 was photoinhibited only at the highest growth irradiance tested $\left(450 \mu \mathrm{E} \mathrm{m} \mathrm{m}^{-2} \mathrm{~s}^{-1}\right)$. Thus, the differences between $P$. marinus MED4 and $P$. marinus SS120 could reflect differences between populations collected from different depths rather than different geographical locations.

For all 3 picoplankters, light-limited growth rates in blue light were higher than at the same irradiance of white light (Fig. 4). These differences can be explained if we consider the portion of photon flux density in the white light corresponding to the band of transmittance of the blue filters $(47 \%$ of the white light irradiance is between 380 and $540 \mathrm{~nm}$ ). This band of wavelengths includes the wavelengths of absorption by the major photosynthetic pigments: chl $a_{1}$, chl $a_{2}$, chl $b_{2}$, and PUB. The reduced growth rates of cells grown in white light relative to those in blue light can be explained solely on the basis of reduced levels of photosynthetically usable radiation: the graphs 'collapse' onto one another when the white light irradiance is expressed in terms of blue photon flux density (data not shown).

\section{Cellular pigment content}

Concentrations of chlorophylls and carotenoids were determined in light-limited and light-saturated cultures of all 3 picoplankton clones. The major pigments present in Synechococcus WH8103 were chl $a_{1}$, zeaxanthin and $\beta$-carotene, and the major pigments of low-light cultures of Prochlorococcus marinus SS120 and $P$. marinus MED4 were chl $a_{2}$, chl $b_{2}$, a chl $c$-like pigment, zeaxanthin, $\alpha$-carotene, and an unknown carotenoid, consistent with previous reports (Guillard et al. 1985, Goericke \& Repeta 1992). Analysis of the pigments on the C-18 column-based RP-HPLC system also revealed traces of $\beta$-carotene in the $2 P$. marinus clones.

The analysis of high-light cultures of Prochlorococcus marinus SS120 on the C-8 column-based HPLC system revealed 2 partially separated $\mathrm{chl} b$ peaks (Fig. 5a) with on-line absorbance spectra typical of chl $b_{1}$ and chl $b_{2}$ (cf. Goericke \& Repeta 1993). Chl $a_{1}$ was undetectable in these cultures, which would have eluted at $28.9 \mathrm{~min}$, well separated from $\mathrm{chl} \mathrm{a}_{2}$ and its stereoisomer chl $a_{2}^{\prime}$ (Fig. 5a). We isolated chl $a_{2}$ and total $\mathrm{chl} b$ from high-light cultures of the $P$. marinus clone SS120 and recorded their mass spectra to prove 


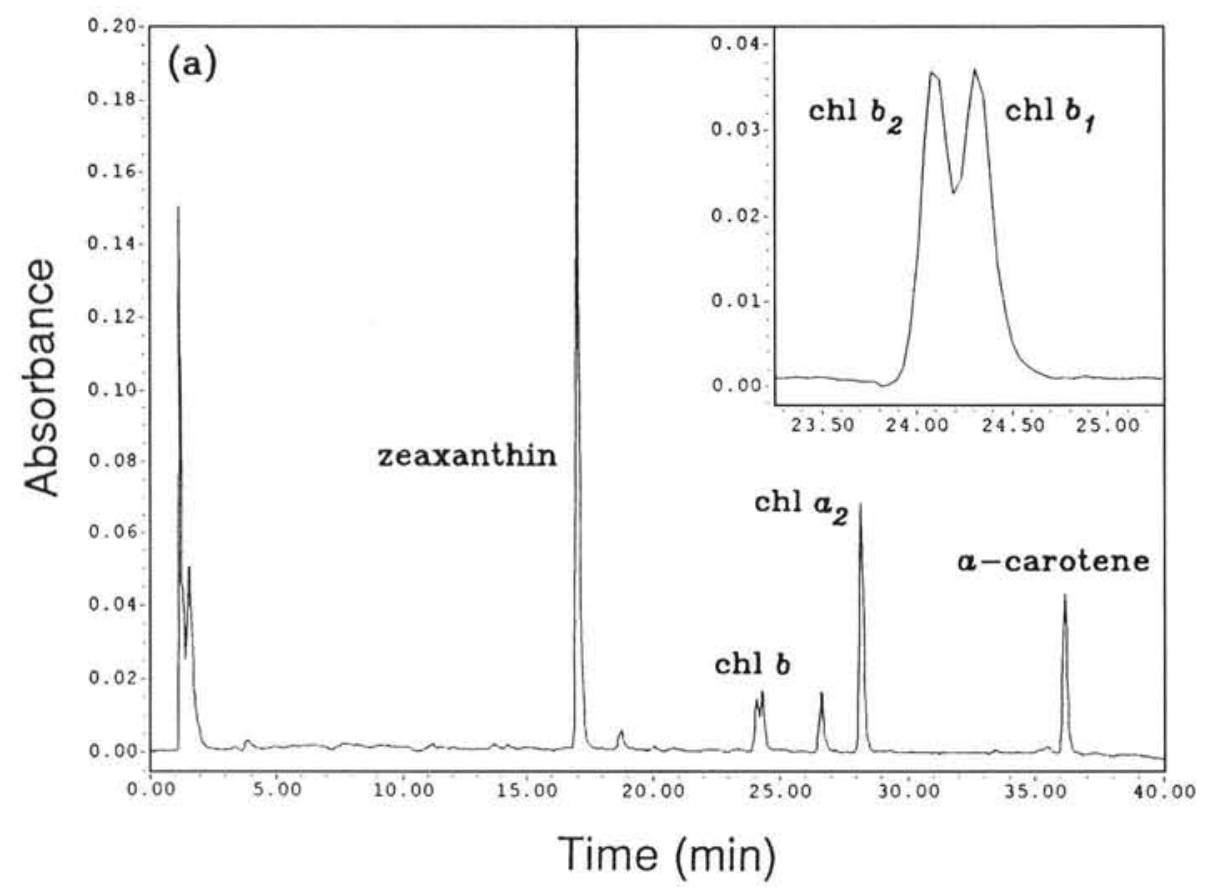

(b)

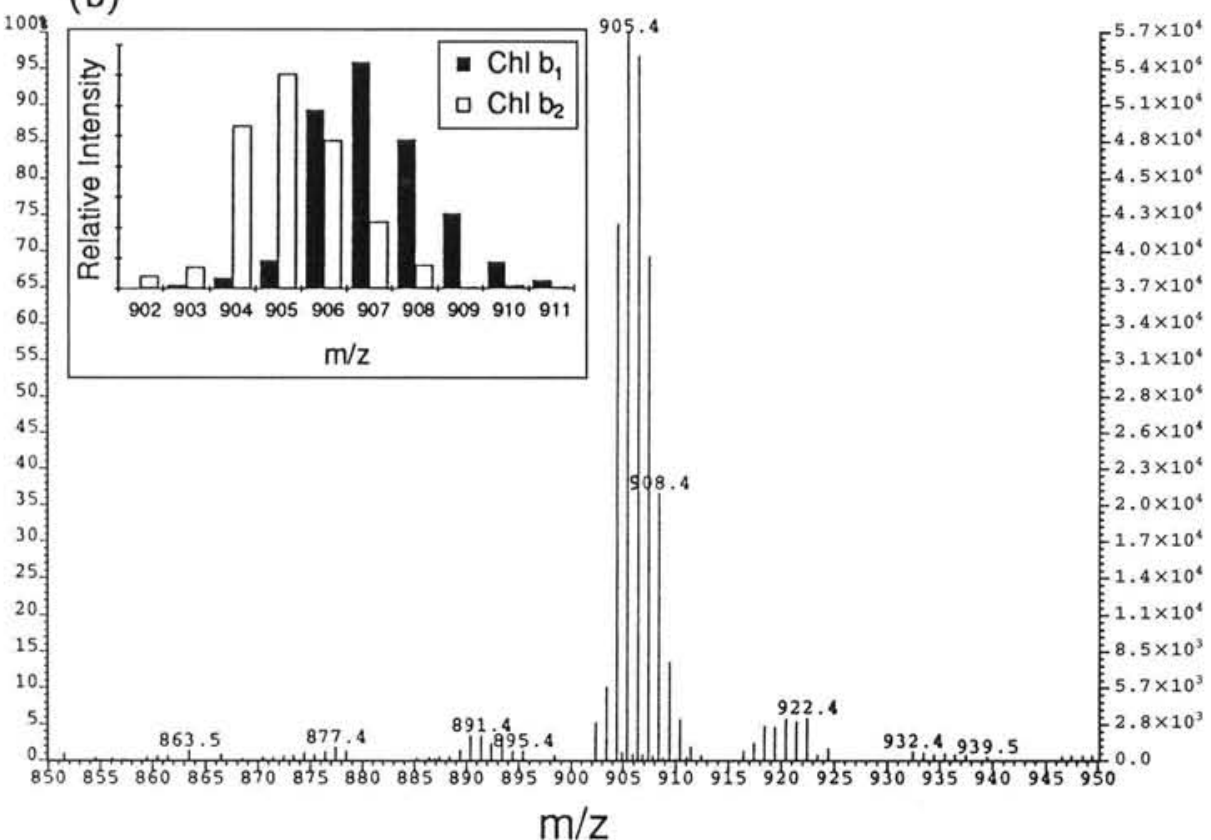

Fig. 5. (a) System II chromatogram (absorbance at $440 \mathrm{~nm}$ ) of the pigments of the Prochlorococcus marinus SS120 grown at $75 \mu \mathrm{E} \mathrm{m}^{-2} \mathrm{~s}^{-1}$ under white light. Inset: partial separation of chl $b_{1}$ and chl $b_{2}$ when absorbance is measured at $473 \mathrm{~nm}$. (b) Mass spectrum of total chl $b$ isolated from high-light cultures of $P$. marinus clone SS120. The cluster at $\mathrm{m} / z \quad 905$ to 907 is due to chl $b_{1}$ and chl $b_{2}$ as demonstrated from the deconvoluted spectra (inset) which are identical to the spectra of $\mathrm{chl} b_{1}(\mathrm{~m} / \mathrm{z}$ $907)$ and $c h l ~ b_{2}(m / z$ 905)

the presence of these pigments and the absence of chl $b_{2}$ allomers. The major ion in the mass spectrum of chl $a_{2}$ was $m / z$ 891, consistent with its molecular ion. The dominant peak in the mass spectrum of total chl $b$ was a cluster around $\mathrm{m} / \mathrm{z} 903$ to 909 (Fig. 5b); notably absent were major signals at $\mathrm{m} / \mathrm{z} 921,934$ and 937 , which would have corresponded to the allomers of chl $b_{2}$ (cf. Otsuki et al. 1987). Using least-squares analysis, the cluster at $\mathrm{m} / \mathrm{z} 903$ to 909 was deconvo- luted into $2 \mathrm{chl} b$ spectra with molecular ions at $\mathrm{m} / \mathrm{z}$ 905 and 907 (Fig. 5b, inset), which correspond to the molecular ions of chl $b_{2}$ and chl $b_{1}$, respectively.

The relative concentrations of $\mathrm{chl} b_{1}$ and $\mathrm{chl} b_{2}$ were determined in all cultures by recording the ratio of the integrated total chl $b$ absorbances at 468 and $478 \mathrm{~nm}$ $\left(\mathrm{A}_{468} / \mathrm{A}_{478}\right)$. The ratios of the integrated absorbances at 468 and $478 \mathrm{~nm}$ were $1.229 \pm 0.004$ (standard deviation) for pure chl $b_{1}$ isolated from higher plants and 


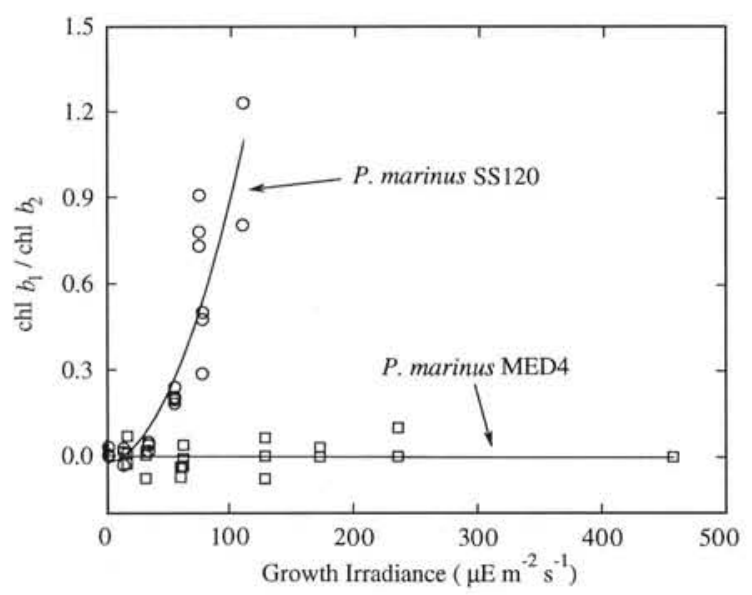

Fig. 6. Ratio of chl $b_{1}$ to chl $b_{2}$ in Prochlorococcus marinus SS120 (O) and P. marinus MED4 (ㅁ) grown under white light

$0.837 \pm 0.004$ for pure chl $b_{2}$ isolated from the corn mutant ON8147 (Bazzaz 1981). The chl $b$ from lowlight cultures of Prochlorococcus marinus SS120 $\left(<20 \mu \mathrm{E} \mathrm{m} \mathrm{m}^{-2} \mathrm{~s}^{-1}\right)$ had an average $\mathrm{A}_{468} / \mathrm{A}_{478}$ ratio of $0.84 \pm 0.008(\mathrm{~N}=13)$, a value not significantly different from the value of pure chl $b_{2}(0.10>\mathrm{p}>0.05)$. The ratio increased with increasing growth irradiances, indicating that $P$. marinus $\mathrm{SS} 120$ has measurable amounts of normal chl $b_{1}$ at high light (Fig. 6). Chl $b_{1}$ was not detected in previous analyses of pigment content in the $P$. marinus isolate from the Sargasso Sea because the light level used in those studies (Goericke \& Repeta 1992) was below that at which chl $b_{1}$ begins to be synthesized. In contrast, $P$. marinus MED4 does not have any detectable levels of chl $b_{1}$ at any growth irradiances (Fig. 6), as indicated by an average $\mathrm{A}_{468} / \mathrm{A}_{478}$ ratio of $0.839 \pm 0.016(\mathrm{~N}=42)$, a value not significantly different $(p>0.25)$ than the value of 0.837 for pure chl $b_{2}$. The presence of $\mathrm{chl} b_{1}$ in P. marinus SS120 and its absence in $P$. marinus MED4 has been suggested by other researchers (Partensky et al. 1993). For the rest of this paper, references to $\mathrm{chl} b$ in the $P$. marinus data refer to the sum of $\mathrm{chl} b_{1}$ and $\mathrm{chl} b_{2}$ (i.e. total $\mathrm{chl} b$ ) for $P$. marinus SS120 and to chl $b_{2}$ only for P. marinus MED4.

Cellular chl a increased with decreasing light intensity in all 3 picoplankton (Fig. 7A). The chl $a_{2}$ per cell of Prochlorococcus marinus was 2 to 6 times lower than the chl $a_{1}$ of Synechococcus WH8103 at all light intensities. P. marinus MED4 had about 2.5 times the chl $a_{2}$ per cell, but 3 to 10 times less chl $b$ per cell (Fig. 7B), than P. marinus SS120, such that the sum of the chl $a_{2}$ and total chl $b$ was similar for both clones (data not shown). The total chl $b / c h l ~ a_{2}$ ratio for $P$. marinus SS120 was 10 times higher than the chl $b_{2} / \mathrm{chl} a_{2}$ ratio for $P$. marinus MED4 at all growth irradiances, but
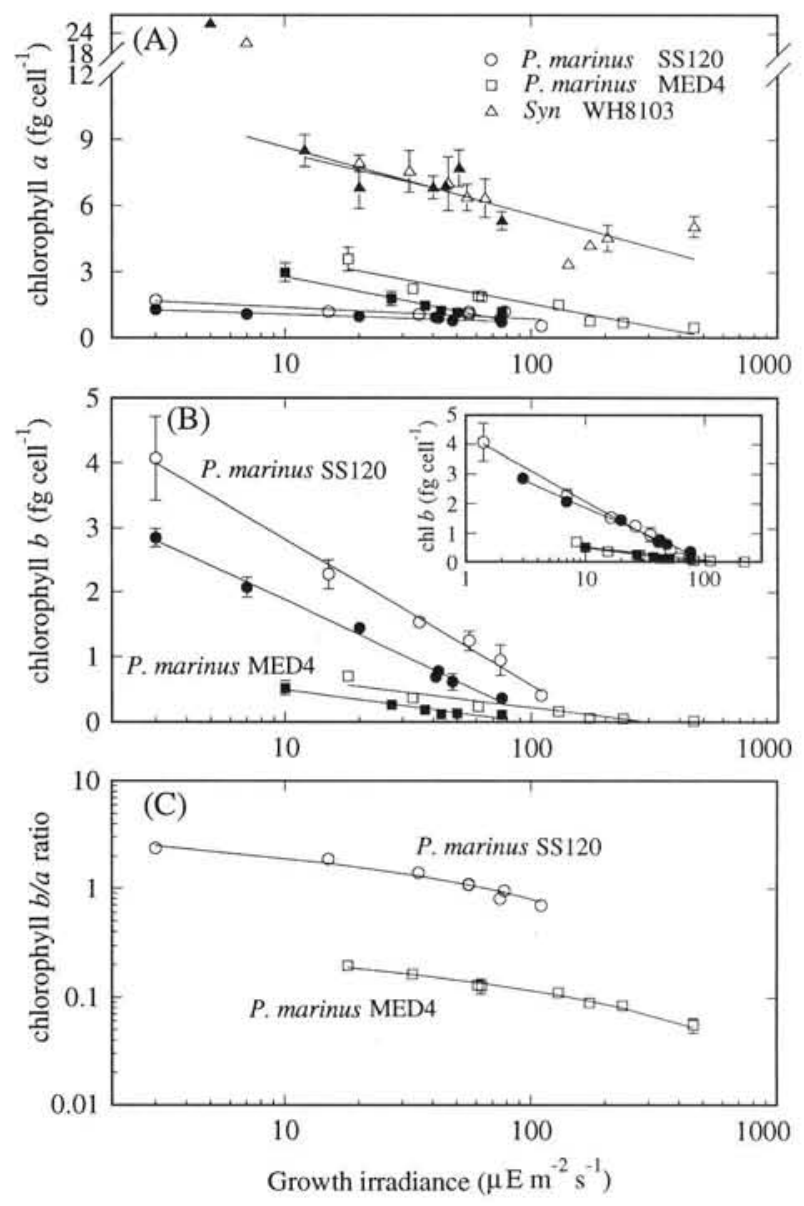

Fig. 7. (A) Cellular chl $a_{1}$ for Synechococcus and chl $a_{2}$ for Prochlorococcus marinus SS120 and P. marinus MED4. (B) Cellular chl $b$ content of both $P$. marinus clones. The inset shows that the total chl $b$ in the $2 P$. marinus clones as a function of blue light and 'corrected' white light (see text) is the same. (C) Ratio of total chl $b$ to chl $a_{2}$ as a function of white growth irradiance for the 2 strains. Symbols for all 3 panels are the same: P. marinus SS120 $(0, \bullet)$, P. marinus MED4 $(\square, \mathbf{m})$ and Synechococcus WH8103 $(\Delta, \mathbf{\Delta})$; open symbols: white light; closed symbols: blue light. Error bars: 1 SD of the mean of 2 or 3 cultures

the percent change in the chl $b / c h l a_{2}$ ratio over the growth irradiance range was the same (Fig. $7 \mathrm{C}$ ).

Depth profiles of chl $b_{2} / \mathrm{chl} a_{2}$ ratios in the field (Goericke \& Repeta 1993) span a range which is greater than the ranges measured here for either of the 2 clones of Prochlorococcus marinus. The range of chl $b_{2} / \mathrm{chl} a_{2}$ ratios measured in the deep euphotic zone of the Sargasso Sea is similar to the range of total $\mathrm{chl} b / \mathrm{chl} a_{2}$ ratio of $P$. marinus SS120 measured under blue and white light ( 0.4 to 2.4$)$, whereas the range found in the surface waters of the Sargasso Sea is more similar to the range measured for $P$. marinus MED4 grown under blue and white light (0.05 to 0.2) (Goericke \& Repeta 1993). As suggested by Goericke 
\& Repeta (1993), the sharp transition of chl $b_{2} /$ chl $a_{2}$ ratios at depth may be due, in part, to changing populations of differently photoadapted (as opposed to photoacclimated) $P$. marinus populations: in the surface, the $P$. marinus population may consist of low chl $b_{2}$-type cells capable of growth at higher light, similar to $P$. marinus MED4; in the deeper euphotic zone, the population may shift to high chl $b_{2}$-type cells, similar to $P$. marinus SS120.

The chlorophyll content for all 3 picoplankters grown in blue light was lower than that of cultures grown in white light (Fig. 7A, B). When the white light irradiance was corrected for the amount of blue light wavelengths, however, the differences disappeared for the chlorophylls and other pigments (shown for total chl $b$ only; Fig. 7B, inset). Thus, these Prochlorococcus marinus clones do not chromatically adapt to blue light. Rather, they respond to the amount of photosynthetically usable light energy available in both the blue and white light treatments.

Cellular concentrations of zeaxanthin varied by about a factor of 2 in the 2 Prochlorococcus marinus clones and Synechococcus WH8103 (Fig. 8A). The trends range from slightly increasing with irradiance in $P$. marinus SS120 (regression coefficient $=0.005 \pm 0.001 ; \mathrm{p}<0.001$ ) to no obvious variations with growth irradiance in $P$. marinus MED4 and Synechococcus WH8103, with the exception that low-light cultures of Synechococcus WH8103 have relatively high concentrations of zeaxanthin. These data confirm the results of Kana et al. (1988), who showed that cellular concentrations of zeaxanthin do not vary appreciably in nutrient-replete batch cultures of Synechococcus WH7803 grown under a wide range of white light intensities. In contrast to the results of Bidigare et al. (1989b) for Synechococcus WH7803, we found no difference in the average cellular zeaxanthin content for $P$. marinus and Synechococcus WH8103 cells grown in white light and those grown in blue light (blue light data not shown).

The content of zeaxanthin in Synechococcus WH8103 (3.3 $\pm 0.6 \mathrm{fg}$ zeaxanthin cell $\left.^{-1}\right)$ was 1.7 times greater than that reported for Synechococcus WH7803 (Kana et al. 1988) and 3 times the amount in the $P$. marinus clones (Fig. 8A). However, when zeaxanthin content is normalized to estimated cell volume, there is no significant difference between Synechococcus WH8103 and Prochlorococcus marinus. [The volume of Synechococcus WH8103 $\left(0.42 \pm 0.03 \mu^{3}\right.$ cell $\left.^{-1}\right)$ is estimated to be 3.2 times greater than that of $P$. marinus $\left(0.13 \pm 0.01 \mu^{3}\right.$ cell $\left.^{-1}\right)$; Morel et al. 1993]. In addition, a significant, positive correlation $(\mathrm{p}<0.01)$ was found between cellular zeaxanthin and the forward light scatter signal on the flow cytometer for all 3 organisms (data not shown). When zeaxanthin is normalized to forward light scatter and plotted against growth irradi-
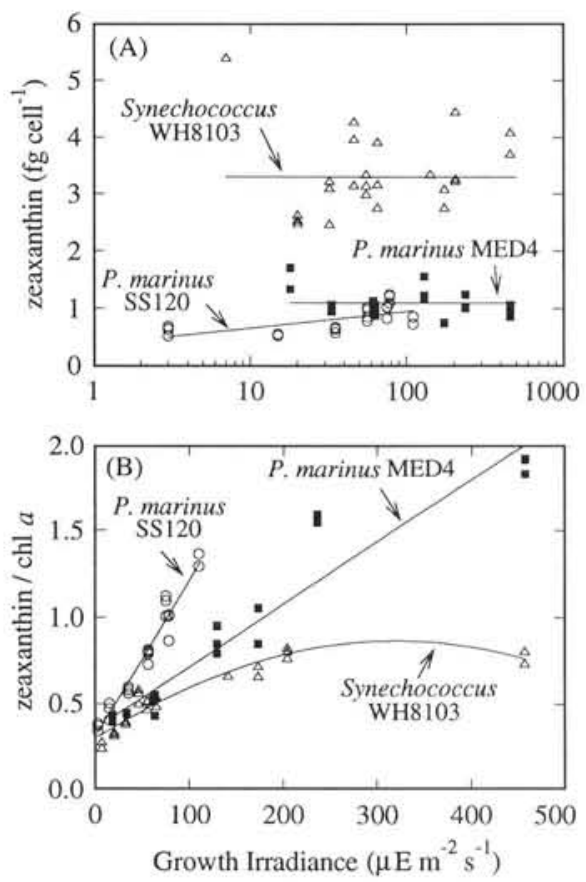

Fig. 8. Change in zeaxanthin and carotenes with change in white light intensity for Synechococcus WH8103 ( $\Delta)$ and the 2 Prochlorococcus marinus clones, SS120 (O) and MED4 (w).

(A) Zeaxanthin per cell, (B) ratio of zeaxanthin to $\mathrm{chl} a$

ance (Goericke pers. comm.), outliers disappear, in particular the low-light-grown Synechococcus WH8103 data points. These results point to the possibility of using zeaxanthin as a marker for prokaryotic biovolume in the field.

For all 3 picoplankton clones, the zeaxanthin to chl a ratio increased (driven by photoacclimative changes in chl a) with increasing growth irradiance (Fig. 8B). At high light intensities, the zeaxanthin/chl a ratio was highest for Prochlorococcus marinus MED4 and began to level off for Synechococcus WH8103. P. marinus SS120 has its highest ratio of zeaxanthin/chl a (about 1.5) at light intensities at which its growth rate was photoinhibited (Fig. 4A).

The $\alpha$-carotene in the Prochlorococcus marinus cultures and the $\beta$-carotene in the Synechococcus cultures covaried with chl a (data not shown) such that the ratio of carotene to chl a was constant over the entire irradiance range for all 3 organisms $(0.26 \pm 0.02$ for $P$. marinus SS120, $0.13 \pm 0.02$ for $P$. marinus MED4, and $0.09 \pm$ 0.01 for Synechococcus WH8103). It is likely that these carotenes are associated with the photosynthetic apparatus, as suggested for $\beta$-carotene in Synechococcus WH7803 (Kana et al. 1988). In addition, both the chl $c$-like pigment and an unknown carotenoid in the $P$. marinus cultures increased with decreasing light (data not shown), also suggesting that these 2 pigments are involved in photosynthesis. 


\section{Flow-cytometrically induced red fluorescence}

As expected, the mean red fluorescence per cell increased with decreasing growth irradiance in all 3 organisms (Fig. 9A, B). Prochlorococcus marinus SS120 had a greater mean cellular red fluorescence at a given irradiance than $P$. marinus MED4 (Fig. 9A) and the change in fluorescence per unit chl $a$ was larger in P. marinus SS120 than P. marinus MED4 (Fig. 10A). This difference is reduced when fluorescence was normalized to the sum of chl $a_{2}$ and total chl $b$ (Fig. 10B), as expected since the sum of total chlorophylls is the same for the 2 strains. However, the difference is not totally eliminated by this normalization. Even if the red fluorescence is plotted against the sum of all the pigments except zeaxanthin, the difference in slopes still exists $(\mathrm{p}<0.001)$. P. marinus SS120 has a greater change in red fluorescence per pigment content because it absorbs more light than $P$. marinus MED4 at $488 \mathrm{~nm}$ (see below), which is the wavelength of the laser line used by the flow cytometer and which
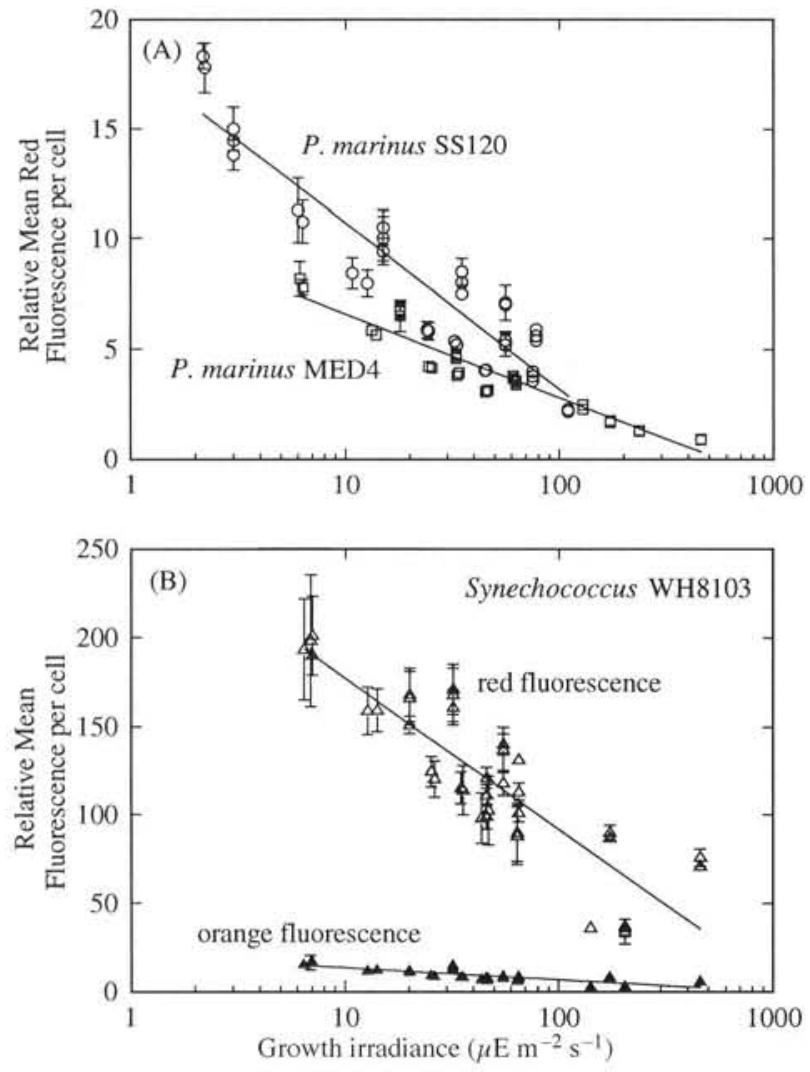

Fig. 9. Flow-cytometrically induced fluorescence per cell as a function of white growth irradiance. Symbols: the mean fluorescence of the population relative to standard beads; error bars: 1 SD of mean fluorescence. (A) Prochlorococcus marinus SS120 (O) and P. marinus MED4 (ㅁ), (B) Synechococcus WH8103. $(\Delta)$ mean red fluorescence per cell; $(\mathbf{A})$ mean orange (phycoerythrin) fluorescence per cell

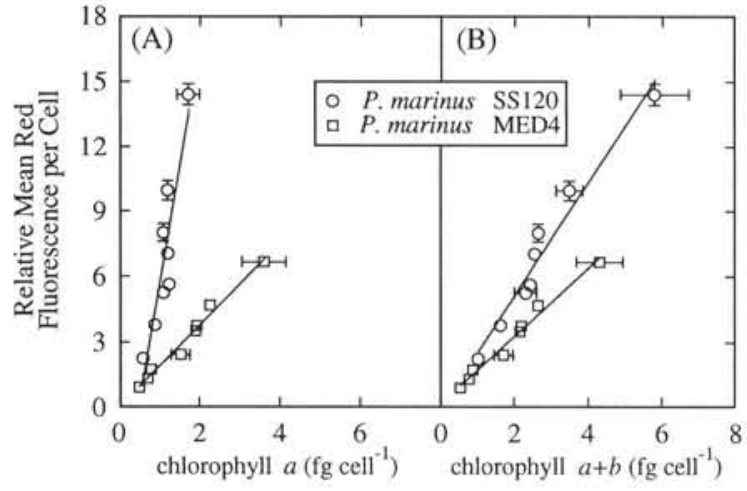

Fig. 10. Relative mean red fluorescence per cell as a function of chlorophyll for both Prochlorococcus marinus clones, SS120 (O) and MED4 (ㅁ) grown under white light intensity.

(A) Cellular chl $a_{2}$, (B) sum of chl $a_{2}$ and total chl $b$ per cell

is close to the in vivo absorption maxima of $\mathrm{chl} \mathrm{a}_{2}$. The linear relationship between the fluorescence and $\operatorname{chl} a_{2}$, and the sum of chl $a_{2}$ and total chl $b$ (Fig. 10), is indicative of a negligible pigment package effect in these small cells (Sosik et al. 1989, Veldhuis \& Kraay 1990, Morel et al. 1993).

In the North Atlantic, the mean red fluorescence of Prochlorococcus marinus has been shown to increase sharply (about 5 -fold) between the 2 and 3\% light levels (Veldhuis \& Kraay 1990). A similar sharp increase in fluorescence with depth was observed in the North Pacific between the 50 and the $120 \mathrm{~m}$ depths (Campbell \& Vaulot 1993). These changes are greater than expected from photoacclimative increases in red fluorescence per cell for either $P$. marinus SS120 or $P$. marinus MED4 alone (Fig. 9A), but might be explained partially by a shift in population from a low chl $b_{2}$-type $P$. marinus population with relatively low mean red fluorescence in the surface waters to a high chl $b_{2}$-type $P$. marinus population with higher mean red fluorescence in the deep euphotic zone. This interpretation of the fluorescence data from field measurements is consistent with observations by other authors (Campbell \& Vaulot 1993, Goericke \& Repeta 1993, Veldhuis \& Kraay 1993) and the possible existence of 2 (or more) strains of $P$. marinus which coexist in the same water column.

\section{Chlorophyll-specific absorption}

For all 3 picoplankters, the main blue absorption peak in the in vivo chl a-specific absorption $\left(a^{*} \mathrm{ph}\right)$ spectrum decreased with decreasing growth irradiance, except for low-light cultures of Prochlorococcus marinus SS120 (Fig. 11A to C). As irradiance levels decreased, absorption due to total chl $b$ (at 480 and $657 \mathrm{~nm}$ ) increased relative to the chl $a_{2}$ absorption (at 449 and $673 \mathrm{~nm}$ ) in 

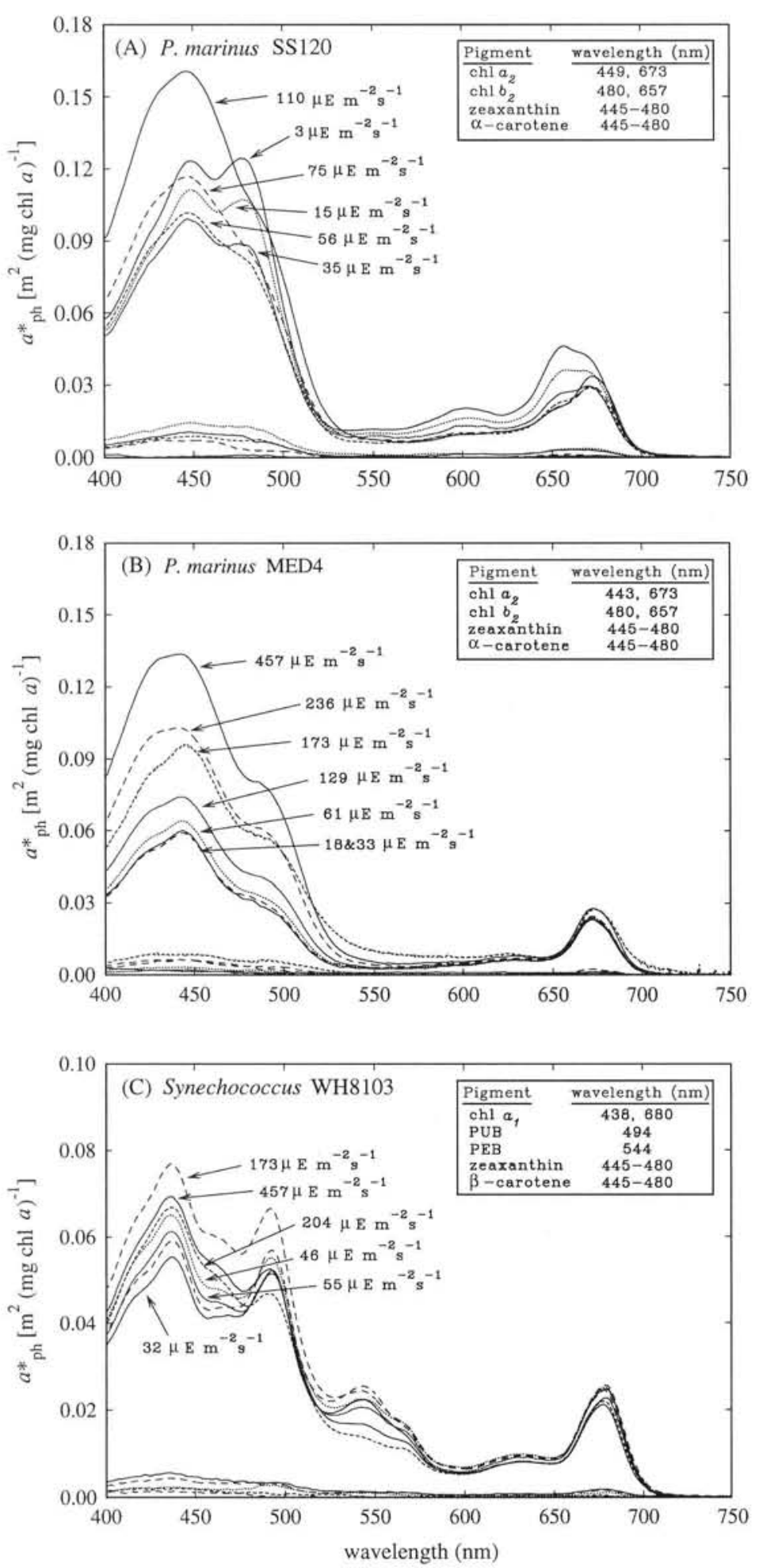

Fig. 11. In vivo chl a-specific absorption spectra $\left\{a^{*}{ }_{\mathrm{ph}}\left[\mathrm{m}^{2}(\mathrm{mg} \mathrm{chl} a)^{-1}\right]\right\}$ for all 3 picophytoplankters. Wavelengths of maximum absorption for the various pigment peaks are listed in the insets (PEB: phycoerythrobilin; PUB: phycourobilin). Each line corresponds to an average spectrum of 2 or 3 cultures grown at different white-light irradiances. Lines at the bottom correspond to the standard deviation of each average spectrum. (A) Prochlorococcus marinus SS120, (B) P. marinus MED4, (C) Synechococcus WH8103
$P$. marinus SS120, resulting in an apparent increase in the height of the chl $a_{2}$ absorption peak in the blue as well as in the red (Fig. 11A). For P. marinus MED4, there was no change in the relative peak heights at 480 and $443 \mathrm{~nm}$ with changing growth irradiance (Fig. 11B) because the ratio of $\mathrm{chl} b_{2}$ to $\mathrm{chl} \mathrm{a}_{2}$ is relatively small (Fig. $7 \mathrm{C}$ ). The blue absorption of chl $a_{1}$ in Synechococcus WH8103 also decreased slightly as growth irradiance decreased (Fig. 11C), although not to the same extent and not as systematically as for $P$. marinus MED4. Overall, $P$. marinus SS120 had a higher $a^{*}{ }_{\mathrm{ph}}$ in the blue wavelengths than Synechococcus WH8103.

To quantify the contribution of various pigments to the absorption spectra of Prochlorococcus marinus, absorption spectra were reconstructed from knowledge of the concentration of the individual pigments and their respective extinction coefficients. (Absorption spectra for Synechococcus WH8103 were not reconstructed because the phycobiliproteins were not measured.) Reconstructed absorption spectra for both $P$. marinus clones grown at high and low light levels closely matched the measured in vivo absorption spectra $\left[\mathrm{a}_{\mathrm{ph}}(\lambda), \mathrm{m}^{-1}\right.$; not normalized to $\mathrm{chl} \mathrm{a}_{2}$ ] (Fig. 12A to D). The contribution by the individual pigments in each reconstructed spectrum reveals that the non-photosynthetic pigment, zeaxanthin, is a major contributor to absorption at both high and low irradiances in P. marinus. At the high growth irradiances, zeaxanthin absorption contributed 40 and $50 \%$ to the total absorption at 449 and $443 \mathrm{~nm}$ in $P$. marinus SS120 and $P$. marinus MED4, respectively (Fig. 12A, C). High contributions of nonphotosynthetic pigment absorption to total absorption could have important implications for estimates of primary productivity and photosynthetic quantum yield (Bidigare et al. 1987, 1989b).

At the lowest growth irradiances, the zeaxanthin contribution to the total absorption at $443 \mathrm{~nm}$ decreased to $30 \%$ and $\mathrm{chl} \mathrm{a}_{2}$ increased to $51 \%$ of the total in Prochlorococcus marinus MED4; chl $b_{2}$ contributed $\leq 5 \%$ of the total absorption at $448 \mathrm{~nm}$ over all irradiance levels (Fig. 12C, D). The shoulder at $480 \mathrm{~nm}$ for $P$. marinus MED4 is due primarily to the second absorption peak of zeaxanthin, not chl $b_{2}$ (Fig. 12C, D). In lowlight $P$. marinus SS120, the absorption peak at $449 \mathrm{~nm}$ is due to $42 \%$ absorption by chl $b_{2}$, 
Fig. 12. Comparison of the in vivo absorption spectra, $a_{\mathrm{ph}}(\lambda), \mathrm{m}^{-1}$, and respective reconstructed absorption spectra for high- and low-lightgrown Prochlorococcus marinus cultures. Different pigments are designated by the same line types as used in Fig. 2. Only the pigments with the greatest contribution to the total absorption are indicated. (A) P. marinus SS120 grown at $75 \mu \mathrm{E} \mathrm{m}^{-2} \mathrm{~s}^{-1}$, (B) P. marinus SS120 grown at $3 \mu \mathrm{E} \mathrm{m} \mathrm{m}^{-2} \mathrm{~s}^{-1}$, (C) P. marinus MED4 grown at $173 \mu \mathrm{E} \mathrm{m}^{-2} \mathrm{~s}^{-1}$, (D) P. marinus MED4 grown at $18 \mu \mathrm{E} \mathrm{m}^{-2} \mathrm{~s}^{-1}$
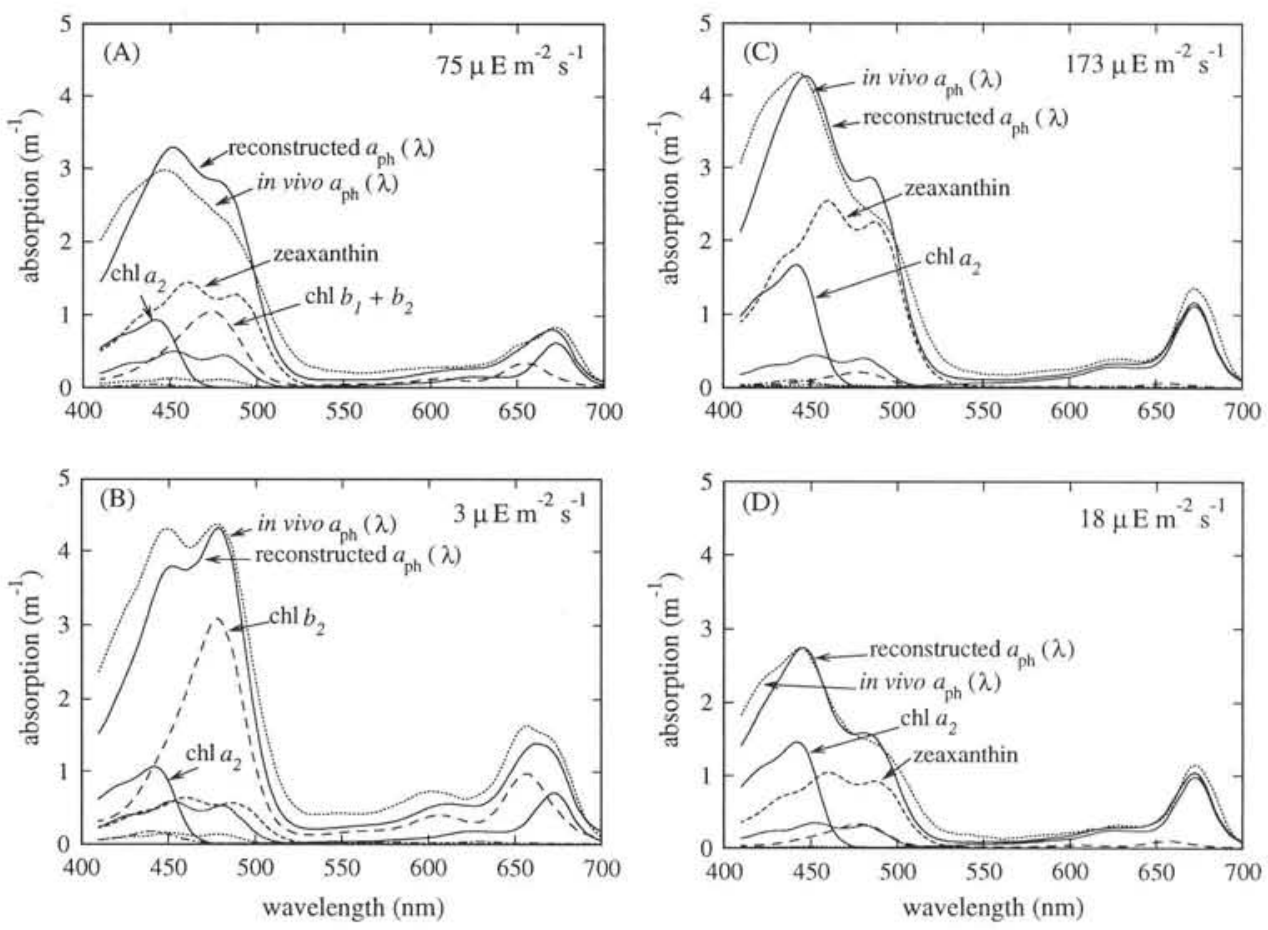

$20 \%$ absorption by chl $a_{2}$, and only $15 \%$ absorption by zeaxanthin (Fig. 12B). Thus, the large amount of absorption by chl $b_{2}$ at low growth irradiances keeps the absorption in the blue at relatively high values (Fig. 11A). For both P. marinus clones, absorption by $\alpha$-carotene at the chl $a_{2}$ blue peak wavelength was 10 to $15 \%$ and that due to an unknown carotenoid and the chl $c$-like pigment was less than $5 \%$ over the range of growth irradiances (Fig. 12A to D).

The slight differences between the in vivo and the reconstructed absorption spectra could be due to several factors: (1) the wavelength shifts assumed for calculating $a_{i}(\lambda)$ may not be precisely correct; $(2)$ we used the 662 and $653 \mathrm{~nm}$ extinction coefficients for chl $a_{2}$ and chl $b_{2}$, respectively (Goericke \& Repeta 1993), which differ slightly from those measured by Shedbalkar \& Rebeiz (1992); (3) imprecision in the correction of the filter absorption spectra may result in differences in the magnitude of absorption. Still, the close match between the reconstructed absorption spectra and the in vivo absorption spectra, in particular the lack of 'flattening' of absorption in the blue, is consistent with the findings of Morel et al. (1993) that the package effect in Prochlorococcus marinus is minimal. Bidigare et al. (1989b) concluded the same for Synechococcus WH7803 using similar methods.

The photoacclimative changes in chl a absorption peak height, quantified above using reconstructed absorption spectra, can also be illustrated by plotting the light-dependent ratio of chl a absorption in the blue relative to that in the red (B/R ratio; Mitchell \&
Kiefer 1988) (Fig. 13). For all 3 phytoplankters, the B/R ratio increased with increasing growth irradiance reflecting the trend in zeaxanthin to $\mathrm{chl}$ a ratio (Fig. 8B). Prochlorococcus marinus had a B/R ratio that increased to 5 as growth irradiance increased (see also Partensky et al. 1993), whereas 'typical' eukaryotic phytoplankton have B/R ratios of less than 2.5 (SooHoo et al. 1986, Maske \& Haardt 1987, Mitchell \& Kiefer 1988).

Several factors contribute to high B/R ratios in Prochlorococcus marinus. First, the ratios of accessory pigments (particularly chl $b_{2}$ and zeaxanthin) to chl $a_{2}$ are

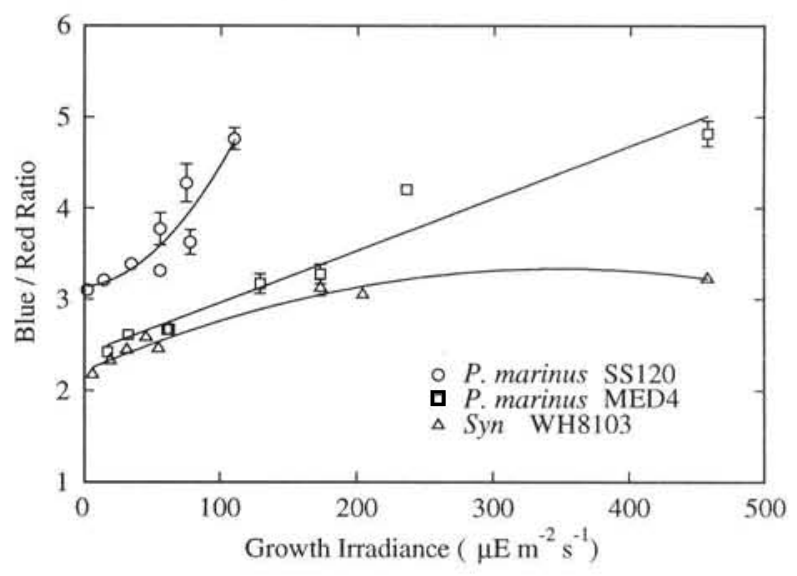

Fig. 13. B/R ratio (chl a absorption peak in the blue relative to that in the red) as a function of white growth irradiance. Prochlorococcus marinus SS120 (O), P. marinus MED4 (ㅁ), and Synechococcus WH8103 ( $\Delta)$ 
high. Secondly, the B/R ratio of pure chl $a_{2}$ and chl $b_{2}$ in solvent (diethyl ether) is about 15 and $50 \%$ higher than that for chl $a_{1}$ and chl $b_{1}$, respectively (see also Bazzaz 1981). Higher specific absorption in the blue wavelengths for chl $a_{2}$ and $\mathrm{chl} b_{2}$ would provide an added advantage for $P$. marinus to absorb blue light relative to other phytoplankton. Thirdly, the small size of $P$. marinus results in a smaller package effect relative to most other phytoplankton and, hence, less flattening of the absorption spectrum in the blue region (Morel et al. 1993, Partensky et al. 1993).

High $\mathrm{B} / \mathrm{R}$ ratios $(>3)$ from in vivo $a^{*}{ }_{\mathrm{ph}}$ measurements (corrected for detrital absorption) have been observed in the Sargasso Sea (Bricaud \& Stramski 1990) and off the coast of southern California (H. Sosik \& B. G. Mitchell unpubl. data) and are likely due to the presense of Prochlorococcus marinus, as hypothesized by Bricaud \& Stramski (1990). In fact, B/R ratio could possibly be used to detect the presence of $P$. marinus in the field when HPLC or flow cytometry is not available.

\section{Chlorophyll a-specific fluorescence excitation}

The fluorescence emission spectra for both Prochlorococcus marinus clones is a single peak at $680 \mathrm{~nm}$, the same wavelength as for Synechococcus WH8103 (data not shown). The chl $a$ normalized fluorescence $\left[F^{*}{ }_{\mathrm{ph}}(\lambda)\right]$ of $P$. marinus SS120 increased as growth irradiance decreased (Fig. 14A), opposite to the trend in $a^{*}{ }_{\mathrm{ph}}(\lambda)$. This increase was due in large part to the increase in chl $b_{2}$ relative to chl $a_{2}$ (Fig. $7 \mathrm{C}$ ), such that below irradiances of $56 \mu \mathrm{E} \mathrm{m} \mathrm{m}^{-2} \mathrm{~s}^{-1}$ the contribution of chl $b_{2}$ to fluorescence excitation exceeded that of $\mathrm{chl} \mathrm{a}_{2}$ (Fig. 14A). In fact, the ratio of the total chl $b F^{*}{ }_{\text {ph }}$ peak at $480 \mathrm{~nm}$ to that of the chl $a_{2} F^{*}{ }^{*}$ ph peak at $443 \mathrm{~nm}$ ( $F$-ratio; Mitchell \& Kiefer 1988) is positively correlated ( $\mathrm{r}=0.87, \mathrm{p}<0.01$ ) with the total chl $b / \mathrm{chl} a_{2}$ ratio for P. marinus SS120 (data not shown). For P. marinus MED4, the differences between high- and lowlight chl $a_{2} F^{*}{ }_{\mathrm{ph}}(\lambda)$ peaks are small compared to
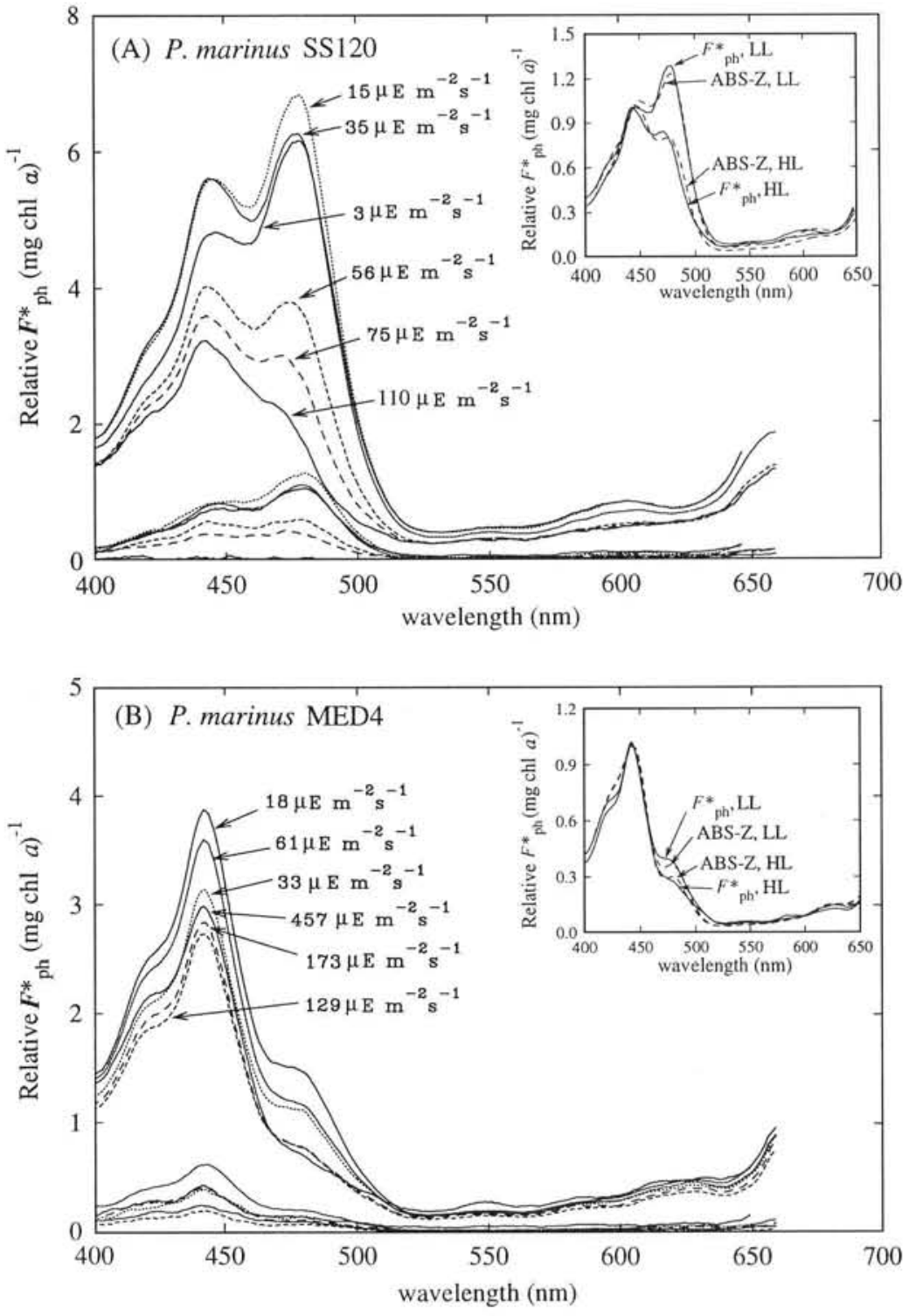

Fig. 14. Chl a-specific fluorescence excitation spectra at different growth irradiances. Fluorescence emission was measured at $680 \mathrm{~nm}$. Each line corresponds to an average spectrum of 2 or 3 cultures grown at different white-light irradiances. Lines at the bottom (below a relative fluorescence of 1) correspond to the standard deviation of the average spectrum. (A) Prochlorococcus marinus SS120, (B) P. marinus MED4. Inset: comparison of $F^{*}{ }_{\mathrm{ph}}(\lambda)$ and chl a-specific reconstructed spectra, ABS-Z, generated by subtracting the zeaxanthin absorption from the reconstructed absorption and dividing by chl $a_{2}$ content at high (HL) and low (LL) light intensities. $F^{\cdot}{ }_{\mathrm{ph}}(\lambda)$ was normalized to the chl $a_{2}$ peak of

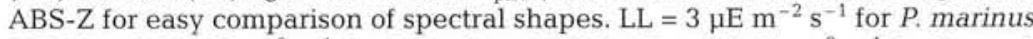
$\mathrm{SS} 120$ and $18 \mu \mathrm{E} \mathrm{m}^{-2} \mathrm{~s}^{-1}$ for $P$. marinus MED4; $\mathrm{HL}=75 \mu \mathrm{E} \mathrm{m} \mathrm{m}^{-2} \mathrm{~s}^{-1}$ for $P$. marinus SS120 and $173 \mu \mathrm{E} \mathrm{m}^{-2} \mathrm{~s}^{-1}$ for $P$. marinus MED4

differences of the chl $a_{2} a^{*}$ ph peak. However, fluorescence emission due to chl $b_{2}$ absorption $F^{*}$ ph $(480 \mathrm{~nm})$ was apparent when $P$. marinus MED4 was grown at low irradiances (Fig. 14B).

The opposite trend in the magnitude of the chl $a_{2}$ peak in fluorescence excitation spectra relative to the 
absorption spectra can be explained more fully by considering the non-photosynthetic role of zeaxanthin (Kana et al. 1988, Bidigare et al. 1989b). The fluorescence excitation spectra should be spectrally similar to the absorption spectra only if the light absorbed by the accessory pigments (e.g. chl $b_{2}$ ) is transferred with high (and equal) efficiency to chl $a_{2}$. Pigments not connected with the photosynthetic apparatus will not be observed in the excitation spectrum. To verify that zeaxanthin does not contribute to $\mathrm{chl} \mathrm{a}_{2}$ fluorescence, we subtracted zeaxanthin absorption from the chl anormalized reconstructed absorption spectra (ABS-Z) and compared this to the corresponding measured $F^{*}{ }^{*}(\lambda)$ at both high and low growth irradiances. The comparison revealed that ABS-Z spectra for both Prochlorococcus marinus clones was spectrally similar to the measured $F^{*}{ }_{\mathrm{ph}}(\lambda)$, even when considering spectral distortion in $F^{*}{ }_{\mathrm{ph}}(\lambda)$ due to the preservation process (see 'Methods'). Furthermore, the trend of decreasing absorption in the blue with decreasing irradiance (Fig. 11A, B) was eliminated for P. marinus MED4 and reversed for $P$. marinus SS120, as was seen for $F^{*}{ }_{\mathrm{ph}}(\lambda)$. This indicates that zeaxanthin does not contribute to fluorescence emission, consistent with the nonphotosynthetic role of zeaxanthin suggested by other authors (Kana et al. 1988, Bidigare et al. 1989b).

\section{CONCLUSIONS}

Prochlorococcus marinus SS120 is adapted to growth at low light, relative to Synechococcus WH8103 (Fig. 4, Table 1). This result supports observations that $P$. marinus is a very abundant (Olson et al. 1990) and fast-growing (Goericke \& Welschmeyer 1993) picoplankter in the deep euphotic zone of the Sargasso Sea. A high abundance of $P$. marinus has been observed in the deep euphotic zone in other oceanic regions as well: the eastern North Atlantic (Veldhuis et al. 1993), the Red Sea (Veldhuis \& Kraay 1993), the North Pacific (Campbell \& Vaulot 1993) and the equatorial Pacific (R. Olson, E. Zettler, J. Dusenberry \& B. Binder unpubl. obs.). Thus, it is likely that strains similar to $P$. marinus SS120 are present in these locations as well.

Differences in seasonal and latitudinal distributions of Prochlorococcus marinus and Synechococcus in the Sargasso Sea cannot be explained by the temperaturedependent growth responses observed in this study (Fig. 3). Other factors, such as nutrient availability, are likely to be important environmental determinants. In the North Atlantic, P. marinus appear to be limited to regions with temperatures above 15 to $18^{\circ} \mathrm{C}$ (Olson et al. 1990, Veldhuis et al. 1993). The presence of $P$. marinus strains other than those used in this study also may account for the different latitudinal and seasonal distributions observed in the North Atlantic.

The 2 clones of Prochlorococcus marinus used in this study differ significantly in their physiological responses to light. $P$. marinus MED4 is high-light adapted, exhibiting a light-dependent growth response similar to Synechococcus WH8103 (isolated from the surface of the Sargasso Sea), whereas P. marinus SS120 is lowlight adapted. $P$. marinus MED4 has significantly reduced levels of $\mathrm{chl} b_{2} / \mathrm{chl} a_{2}$ relative to $P$. marinus $\mathrm{SS} 120$, which results in different absorption and fluorescence properties. Gene sequence analysis of the rpoC1 RNA polymerase gene indicates that these $2 P$. marinus clones are more divergent than 2 heterocyst-forming cyanobacteria from different morphological groups (Palenik \& Haselkorn 1992), supporting the idea that these 2 P. marinus isolates are genetically distinct. On the other hand, these isolates are only $1.2 \%$ divergent in the slower-evolving $16 \mathrm{~S}$ ribosomal RNA gene (E. Urbach unpubl. data), which suggests that these 2 clones are monophyletic. Analysis of $16 \mathrm{~S}$ ribosomal RNA, psbB and combined petB and petD gene sequences has revealed that these 2 clones and other $P$. marinus isolates form a phylogenetic cluster (E. Urbach unpubl. data), suggesting that they should be considered a single genus, and possibly a single species. Further studies of the phylogenetic diversity of these organisms are needed to explore this issue.

It is possible that the differences in the physiological response to light between Prochlorococcus marinus SS120 and $P$. marinus MED4 are not due solely to the fact that they were isolated from 2 geographically distinct regions, but reflect the depth from which each was isolated. Several lines of evidence suggest that at least 2 strains of $P$. marinus may coexist at a given locality, and that these strains may be photoadapted for high and low light in ways that are similar to $P$. marinus MED4 and $P$. marinus SS120, respectively. (1) $P$. marinus are able to grow in the surface mixed layer of the Sargasso Sea (Goericke \& Welschmeyer 1993), even though the Sargasso Sea P. marinus isolate is photoinhibited at high light. (2) Depth profiles of chl $b_{2} / \mathrm{chl} a_{2}$ in the Sargasso Sea are suggestive of a high chl $b_{2}$-containing $P$. marinus at depth and a low chl $b_{2}$-containing $P$. marinus in the surface (Goericke \& Repeta 1993). (3) At least 2 coexisting populations of $P$. marinus in the deep euphotic zone have been observed based on flow cytometric measurements in the North and South Pacific (Campbell \& Vaulot 1993, B. Binder, R. Olson, J. Dusenberry \& E. Zettler unpubl. obs.), the Red Sea (Veldhuis \& Kraay 1993) and the Sargasso Sea (authors' unpubl. obs.).

The observed variability in chl a-specific absorption and fluorescence excitation spectra as a function of light is due to photoacclimative changes in pigment ratios 
and not to pigment package effect, as evidenced by reconstructed absorption spectra. Our results differ from results for eukaryotic phytoplankton, where the package effect accounts for most of the changes in the blue region (chl a peak) of $a^{*}$ ph (Mitchell \& Kiefer 1988, Berner et al. 1989). Reconstructed absorption spectra for Prochlorococcus marinus indicated that zeaxanthin is a major contributor to the magnitude and changes in the blue region of $a^{*}{ }_{\mathrm{ph}}$ but does not contribute to chlorophyll emission, consistent with a non-photosynthetic role in these organisms (Kana et al. 1988, Bidigare et al. 1989b). Estimates of primary productivity and photosynthetic quantum yields could be incorrect by as much as $50 \%$ if the absorption of light due to zeaxanthin is included. The use of chl a-specific photosynthetically active absorption $\left(a^{*}{ }_{\mathrm{ps}}\right)$ quantified from $F^{*}$ ph $(\lambda)$ to eliminate variability in $a^{*}$ ph due to non-photosynthetically active pigments has been suggested (Sosik \& Mitchell unpubl. data). An additional error in the estimates of primary productivity and quantum yields may occur if an incorrect $\beta$-correction algorithm is used to correct absorption of cells on filters from waters dominated by picoplankton, in particular P. marinus.

In vivo $a^{*}{ }_{p h}$ in the blue for Prochlorococcus marinus is higher relative to that measured for eukaryotes (Maske \& Haardt 1987, Mitchell \& Kiefer 1988, Berner et al. 1989), resulting in a high $B / R$ ratio, which could be used as an indicator of $P$. marinus when more reliable methods of detection, such as flow cytometry or HPLC, are unavailable. The high $a^{*}{ }_{\mathrm{ph}}$ in the blue is due not only to high pigment-specific absorption by accessory pigments but also to the small cell size of P. marinus (Morel et al. 1993). The small cell size and chl $b_{2}$ content of $P$. marinus, particularly $P$. marinus SS120, are key features which give $P$. marinus a competitive advantage over Synechococcus and other phytoplankton in the deeper euphotic zone where nutrients are relatively available.

Acknowledgements. This work was supported in part by NSF BSR 9020254, OCE 9000043, OCE 9012117, OCE 9022285. DIR 9101361 and MIT Sloan and Volvo Funds to S.W.C. and NSF grant OCE 91-01384 to D. Repeta and R.G. We thank Carl Johnson for his help with the mass-spec analysis, Neil Blough for the generous use of his spectrofluorometer, and Heidi Sosik and B. Greg Mitchell for helpful discussions about $\beta$ corrections and absorption spectra. We also thank Brian Binder, Neil Blough, Rob Olson and B. Greg Mitchell for critical review of the manuscript.

\section{LITERATURE CITED}

Bazzaz, M. B. (1981). New chlorophyll chromophores isolated from a chlorophyll-deficient mutant of maize. Photobiochem. Photobiophys. 2: 199-207

Berner, T., Dubinsky, Z., Wyman, K., Falkowski, P. G. (1989).
Photoadaptation and the 'package effect' in Dunaliella tertiolecta (Chlorophyceae). J. Phycol. 25: 70-78

Bidigare, R. R., Morrow, J. H., Kiefer, D. A. (1989a). Derivative analysis of spectral absorption by photosynthetic pigments in the western Sargasso Sea. J. mar. Res, 47: 323-341

Bidigare, R. R., Schofield, O., Prezelin, B. B. (1989b). Influence of zeaxanthin on quantum yield of photosynthesis of Synechococcus clone WH7803 (DC2). Mar. Ecol. Prog. Ser. 56: $177-188$

Bidigare, R. R., Smith, R. C., Baker, K. S., Marra, J. (1987). Oceanic primary production estimates from measurements of spectral irradiance and pigment concentrations. Global biogeochem. Cycles 1: 171-186

Bricaud, A., Stramski, D. (1990). Spectral absorption coefficients of living phytoplankton and nonalgal biogenous matter; a comparison between the Peru upwelling area and the Sargasso Sea. Limnol. Oceanogr. 35(3): $562-582$

Campbell, L., Holla, H. A., Vaulot, D. (1994). The importance of Prochlorococcus to community structure in the central North Pacific Ocean. Limnol. Oceanogr. (in press)

Castenholtz, R. W., Waterbury, J. B. (1989). Taxa of the Cyanobacteria in Bergey's 9th edn, Vol. III. Williams \& Wilkins, Baltimore, p. 1727-1738

Chavez, F. P., Buck, K. R., Coale, K., Martin, J. H., DiTullio, G. R., Welschmeyer, N. A., Jacobson, A. C., Barber, R. T. (1991). Growth rates, grazing, sinking and iron limitation of equatorial Pacific phytoplankton. Limnol. Oceanogr. 36: 1816-1833

Chisholm, S. W., Frankel, S. L., Goericke, R., Olson, R. J., Palenik, B., Waterbury, J. B., West-Johnsrud, L., Zettler, E. R. (1992). Prochlorococcus marinus nov. gen. nov. sp.: a marine prokaryote containing divinyl chlorophyll $a$ and $b$. Arch. Microbiol. 157: 297-300

Chisholm, S. W., Olson, R. J., Zettler, E. R., Goericke, R., Waterbury, J. B., Welschmeyer, N. A. (1988). A novel freeliving prochlorophyte abundant in the oceanic euphotic zone. Nature 334: 340-343

Cleveland, J. S., Weidemann, A. D. (1993). Quantifying absorption by aquatic particles: a multiple scattering correction for glass-fiber filters. Limnol. Oceanogr. 38: 1321-1327

DiTullio, G. R., Hutchins, D. A., Bruland, K. W. (1992). Interaction of iron and major nutrients controls phytoplankton growth and species composition in the tropical North Pacific Ocean. Limnol. Oceanogr. 38: 495-508

Goericke, R., Repeta, D. J. (1992). The pigments of Prochlorococcus marinus: the presence of divinyl chlorophyll a and $b$ in a marine procaryote. Limnol. Oceanogr. 37(2): $425-433$

Goericke, R., Repeta, D. J. (1993). Chlorophylls $a$ and $b$ and divinyl chlorophylls $a$ and $b$ in the open subtropical North Atlantic Ocean. Mar. Ecol. Prog. Ser. 101: 307-313

Goericke, R., Welschmeyer, N. A. (1993). The marine prochlorophyte Prochlorococcus contributes significantly to phytoplankton biomass and primary production in the Sargasso Sea. Deep Sea Res. 40: 2283-2294

Guillard, R. R. L., Murphy, L. S., Foss, P., Liaaen-Jensen, S. (1985). Synechococcus spp. as likely zeaxanthin-dominant ultraphytoplankton in the North Atlantic. Limnol Oceanogr. 30: 412

Jerlov, N. G. (1976). Marine optics. Elsevier Scientific Publ., New York, p. 231

Kana, T. M., Glibert, P. M. (1987). Effects of irradiances up to $2000 \mu \mathrm{E} \mathrm{m} \mathrm{m}^{-2} \mathrm{~s}^{-1}$ on marine Synechococcus WH7803 - 1 . Growth, pigmentation, and cell composition. Deep Sea Res. 34(4): 479-495 
Kana, T. M., Glibert, P. M., Goericke, R., Welschmeyer, N. A. (1988). Zeaxanthin and $\beta$-carotene in Synechococcus WH7803 respond differently to irradiance. Limnol. Oceanogr. 33(6): 1623-1627

Mann, J. E., Myers, J. (1968). On pigments, growth, and photosynthesis of Phaeodactylum tricornutum. J. Phycol. 4: 349-355

Maske, H., Haardt, H. (1987). Quantitative in vivo absorption spectra of phytoplankton: detrital absorption and comparison with fluorescence excitation spectra. Limnol. Oceanogr. 32(3): 620-633

Melhuish, W. H. (1962). Calibration of spectrofluorometers for measuring corrected emission spectra. J. Optical Soc. Am. 52(11): 1256-1258

Mitchell, B. G. (1990). Algorithms for determining the absorption coefficient of aquatic particulates using the quantitative filter technique (QFT). SPIE Ocean Optics 1302: $137-148$

Mitchell, B. G., Kiefer, D. A. (1988). Chlorophyll a specific absorption and fluorescence excitation spectra for lightlimited phytoplankton. Deep Sea Res. 35(5): 639-663

Morel, A., Ahn, Y., Partensky, F., Vaulot, D., Claustre, H. (1993). Prochlorococcus and Synechococcus: a comparative study of their optical properties in relation to their size and pigmentation. J. mar. Res. 51: 617-649

Neveux, J., Vaulot, D., Courties, C., Fukai, E. (1989). Green photosynthetic bacteria associated with the deep chlorophyll maximum of the Sargasso Sea. C.r. Acad. Sci. Paris 308: 9-14

Olson, R. J., Chisholm, S. W., Zettler, E. Z., Altabet, M. A., Dusenberry, J. A. (1990). Spatial and temporal distributions of prochlorophyte picoplankton in the North Atlantic Ocean. Deep Sea Res. 37: 1033-1051

Otsuki, A., Watanabe, M. M., Sugahara, K. (1987). Chlorophyll pigments in methanol extracts from ten axenic cultured diatoms and three green algae as determined by reverse phase HPLC with fluorometric detection. J. Phycol. 23: 406-414

Palenik, B., Haselkorn, B. (1992). Multiple evolutionary origins of prochlorophytes, the chlorophyll $b$-containing prokaryotes. Nature 355: 265-267

Partensky, F., Hoepffner, N., Li, W. K. W., Ulloa, O., Vaulot, D. (1993). Photoacclimation of Prochlorococcus sp. (Prochlorophyta) strains isolated from North Atlantic and the Mediterranean Sea. Plant Physiol. 101: 285-296

Shedbalkar, V. P., Rebeiz, C. A. (1992). Chloroplast biogenesis: determination of the molar extinction coefficients

This article was submitted to the editor of divinyl chlorophyll $a$ and $b$ and their pheophytins. Analyt. Biochem. 207: 261-266

Shibata, K. (1958). Spectrophotometry of intact biological materials. Absolute and relative measurements of their transmission, reflection and absorption spectra. J. Biochem. 45: 599-623

SooHoo, J. B., Kiefer, D. A., Collins, D. J., McDermid, I. S. (1986). In vivo fluorescence excitation and absorption spectra of marine phytoplankton: I. Taxonomic characteristics and responses to photoadaptation. J. Plankton Res. 8(1): 197-214

Sosik, H. M., Chisholm, S. W., Olson, R. J. (1989). Chlorophyll fluorescence from single cells: interpretation of flow cytometric signals. Limnol. Oceanogr. 34(8): 1749-1761

Stramski, D. (1990). Artifacts in measuring absorption spectra of phytoplankton collected on a filter. Limnol. Oceanogr. 35(8): 1804-1809

Vaulot, D. (1989). CYTOPC: processing software for flow cytometric data. Signal and Noise 2: 8

Vaulot, D., Courties, C., Partensky, F. (1989). A simple method to preserve oceanic phytoplankton for flow cytometric analyses. Cytometry 10: 629-635

Vaulot, D., Partensky, F. (1992). Cell cycle distributions of prochlorophytes in the northwestern Mediterranean Sea. Deep Sea Res. 39: 727-742

Vaulot, D., Partensky, F., Neveux, J., Mantoura, R. F. C. Llewellyn, C. A. (1990). Winter presence of prochlorophytes in surface waters of the northwestern Mediterranean Sea. Limnol. Oceanogr. 35: 1156-1164

Veldhuis, M. J. W., Kraay, G. W. (1990). Vertical distribution and pigment composition of a picoplanktonic prochlorophyte in the subtropical N. Atlantic: a combined study of HPLC-analysis of pigments and flow cytometry. Mar. Ecol. Prog. Ser. 68: 121-127

Veldhuis, M. J. W., Kraay, G. W. (1993). Cell abundance and fluorescence of picoplankton in relation to growth irradiance and nitrogen availability in the Red Sea. Neth. J. Sea Res. 31: 135-145

Veldhuis, M. J. W., Kraay, G. W., Gieskes, W. W. C. (1993). Growth and fluorescence characteristics of ultraplankton on a north-south transect in the eastern North Atlantic. Deep Sea Res. 40: 609-626

Waterbury, J. B., Watson, S. W., Valois, F. W., Franks, D. G. (1986). Biological and ecological characterization of the marine unicellular cyanobacterium Synechococcus. In: Platt, T., Li, W. K. W. (eds.) Photosynthetic picoplankton. Can. Bull. Fish Aquat. Sci. 214: 71-120

Manuscript first received: December 2, 1993

Revised version accepted: September 12, 1994 